\title{
Desnudando el mito: un balance sobre las tensiones del modelo de conservación en Costa Rica (1970-2015)
}

Undressing myth: a balance of tensions in Costa Rica's conservation model (1970-2015)

DOI: $10.5935 / 2237-2717.20160004$

\author{
Maximiliano López López \\ Observatorio de Historia Agroecológica y Ambiental \\ Universidad Nacional de Costa Rica, Heredia \\ maxmlopez6@gmail.com \\ Costa Rica \\ Roberto Granados Porras \\ Observatorio de Historia Agroecológica y Ambiental \\ Universidad Nacional de Costa Rica, Heredia \\ c.roberth@gmail.com \\ Costa Rica
}

Recibido: 15 de marzo de 2016

Aprobado: 12 de abril de 2016

\section{RESUMEN}

Hace más de tres décadas Costa Rica lanzó un conjunto de estrategias para crear una "marca país" ligada a sus riquezas naturales. El $5 \%$ de la biodiversidad mundial en un territorio reducido, la cercanía entre las costas, la presencia de exuberantes volcanes y la tranquilidad que ofrece un sistema democrático se constituyeron fácilmente en el timón que orientó las políticas públicas relacionadas con la conservación y la promoción del turismo. En este trabajo se pretende hacer una lectura que, sin demeritar los logros alcanzados, nos permita comprender las tensiones y contradicciones que derivan del modelo de conservación y de otras políticas públicas conexas. El estudio realiza un análisis del modelo de conservación implantado en Costa Rica, su estructura piramidal y sus organismos rectores, para luego acercarse a las contradicciones que derivan de la aplicación de políticas públicas que intentan conservar y otras que buscan dar tierra a los campesinos. El artículo desarrolla dos ejemplos breves de las tensiones que se desarrollan en torno a las zonas protegidas y cierra con un balance del aporte económico de las zonas protegidas con el cual se pretende demostrar que ese modelo de conservación responde más a la coyuntura de cambio económico que experimentó el país entre las décadas de 1970 y 1980

\section{Palabras claves}

Conservación,áreas protegidas, historia ambiental, Costa Rica.

\section{ABSTRACT}

More than three decades ago Costa Rica launched a "country brand" which it was linked to its natural resources. $5 \%$ of the global biodiversity in a very small country, the proximity of the coasts, the presence of lush volcanoes and the peace that a democratic system offers were formed by the path that some public policies oriented. These policies were related to the conservation and promotion of the tourism. The purpose of this paper is to have a view that, without discrediting the achievements, allow us to-understand the tensions and contradictions that originate the conservation model and the public policies connected. The study carries an analysis of the conservation model installed in Costa Rica, its pyramidal structure and the governing bodies. After doing this part, analyze the contradictions that were originated by the application of public policies which are trying to conserve and trying to give land to farmers. The article develops two brief examples of the tensions which are established about the protected areas, and it finishes with a balance of the economic contribution of the protected areas with the aim of demonstrating that this conservation model responds to the situation that the country experienced with the economic change between 1970 and 1980.

\section{KEYWORDS}

Conservation, protected areas, environmental history, Costa Rica. 
Existen diversos consensos sobre la situación del ambiente: El primero, y sin duda incuestionable, es que el ecosistema planetario está en crisis. En segundo lugar, que esa crisis deriva del modelo de explotación que caracteriza a la sociedad industrial altamente demandante de recursos y energía. Un tercer punto de encuentro es que se debe actuar pronto para contener el daño y con ello tratar de perpetuar nuestra propia existencia como especie. El informe del Club de Roma o Informe Meadows denominado "Los límites del crecimiento" y publicado en 1972 constituye el primer balance sobre la situación mundial del ambiente y sobre sus posibles implicaciones.

El mismo año que se publicó ese informe se llevó a cabo, en Estocolmo, la Conferencia sobre el Medio Humano, de la cual surgió luego el Programa de Naciones Unidas para el Medio Ambiente (PNUMA). Asimismo, como consecuencia de lo discutido en Estocolmo se publicó en 1987 el denominado Informe Brundtland, en el cual se recogen las principales inquietudes sobre el ambiente y por primera vez se utiliza el concepto de desarrollo sostenible. A partir de entonces la atención sobre el deterioro ambiental se empezó a plasmar en diferentes agendas multilaterales en pro de la conservación, dentro de las cuales marcó pauta la Agenda 21 o Agenda de Río firmada en 1992 y de manera más reciente la Cumbre de Río+20 celebrada en 2012. Está claro, sin embargo, que muchas naciones ya habían iniciado antes con diversas políticas y leyes para contener el daño ambiental, por ejemplo, Brasil emitió su código forestal en 1965.

En el caso concreto de Costa Rica, objeto de nuestra atención, se debe destacar que las acciones impulsadas por esta nación en pro del ambiente se pueden clasificar claramente en al menos tres periodos según los propósitos de cada uno. El primero de ellos, al cual denominaremos de protección de bosques se extiende de $1888^{1}$ hasta 1940. En este se aprecia una clara inclinación por la protección de bosques, con especial interés en las áreas cercanas a los conos volcánicos. En efecto, desde 1903 se había propuesto una iniciativa de ley para dictar un código ambiental y a esto lo siguió la promulgación de la ley de guardabosques emitida en 1906 así como la ley de quemas de 1909. En esa misma línea se dictó la ley de reforestación en 1923, la de explotación de bosques en 1935 y en 1939 se decretó la protección de dos kilómetros en los alrededores de algunos volcanes que rodean el Valle Central. Precisamente, esta última ley preparó el camino para la creación de los primeros parques nacionales.

En el segundo periodo reconocemos una clara intención por la protección del agua y la biodiversidad. Este periodo se puede enmarcar entre 1940 y 1970 y en él es suficiente con mencionar la ley de aguas de 1942, la ley para promover la conservación de los suelos y las aguas dictada en 1952, así como la ley de conservación de la fauna, emitida en 1961. El tercer periodo que identificamos va de 1970 a la actualidad y corresponde a la creación de áreas protegidas. En este periodo las leyes giran en torno a la conservación desde un punto de vista integral para lo cual se definen distintas modalidades de manejo. En la actualidad Costa Rica tiene 8 modalidades de protección, a saber, parques nacionales, reservas biológicas, refugios de vida silvestre, zonas protectoras, reservas forestales, reserva natural absoluta, monumento nacional y humedales (algunos de ellos con denominación RAMSAR).

Es pertinente aclarar que los primeros dos parques nacionales se crearon en $1955 \mathrm{y}$ que algunos de los que se crearon luego como parques nacionales, surgieron primero bajo otra categoría de manejo. Pero sobre lo que se quiere llamar la atención es que, de los 29 parques nacionales con que cuenta el país en la actualidad, el $44,8 \%$ se crearon en la

${ }^{1}$ Interesa destacar 1888 pues tales iniciativas de conservación de bosques se ubican hacia el final del periodo de reformas liberales en Costa Rica que se extendió de 1870 a 1890. 
década de 1970 (13 en total), 10,3\% en los ochentas, ${ }^{2}$ el 20,7\% se constituyó en la década de 1990 y el restante 13,8\% luego del año 2000. A raíz de ese bum de la década de 1970 se promulga de la Ley de Creación de Parques Nacionales (1977), reforzada en 1982 con la Ley para la ampliación de parques nacionales y reservas biológicas. ${ }^{3} \mathrm{~A}$ esto siguieron otros esfuerzos como la Ley para incluir el tema de protección del ambiente como un aspecto obligatorio en la enseñanza primaria y secundaria (1991), hasta llegar a la Ley Orgánica del Ambiente de 1995 y la Ley de Biodiversidad de 1998. ${ }^{4}$ Desde entonces se han realizado diferentes modificaciones al articulado de las leyes emitidas en procura de ajustarlas a las nuevas tendencias en conservación y a las recomendaciones hechas por organismos nacionales e internacionales. Como resultado de esa tendencia, hoy Costa Rica ha suscrito cerca de 50 tratados internacionales en materia ambiental. ${ }^{5}$

\section{La conservación en Costa Rica y sus entes rectores}

Tras conocer los datos ofrecidos anteriormente, cualquiera podría suponer que la estructura administrativa para la protección ambiental en Costa Rica fue determinante en la consecución de esos avances. Sin embargo, aunque hay leyes desde principios de siglo XX y que Costa Rica se unió a la Convención Panamericana sobre la Protección Natural y la Preservación de la Vida Silvestre en el Hemisferio Occidental en 1966, ${ }^{6}$ la protección del ambiente se visualizaba como la suma de espacios sin relación entre sí. La evidencia de ello es que hasta 1988, fue el Ministerio de Agricultura y Ganadería (MAG) el encargado de administrar las zonas protegidas desde tres direcciones distintas, el Servicio Nacional de Parques Nacionales, la Dirección General Forestal y la Dirección de Vida Silvestre. ${ }^{7}$

En 1988 se crea el Ministerio de Recursos Naturales, Energía y Minas (MIRENEM) y este asume las funciones que desempeñaban las direcciones Forestal y de Vida Silvestre. Sin embargo, el Servicio de Parques Nacionales se mantuvo adscrito al MAG hasta 1995, año en que la Ley Orgánica del Ambiente convirtió al MIRENEM en el Ministerio de Ambiente y Energía (MINAE). ${ }^{8}$ El esquema administrativo actual se consolida en 1998 con la creación del Sistema Nacional de Áreas de Conservación como entidad adscrita de manera directa al Ministro de Ambiente y Energía, junto a otras instancias como la Secretaría Técnica Nacional Ambiental y el Tribunal Ambiental Administrativo. Pero más allá de esta compleja trama administrativa, interesa destacar que la idea de protección que se plasma en las prohibiciones $^{9}$ de la Ley del Sistema de Parques Nacionales hacía ver la conservación como

\footnotetext{
${ }^{2}$ Este esfuerzo que realizó el país en la década de 1970 fue compensado en la década de 1980 por una donación de 10 millones de dólares, "la primera gran donación en el mundo otorgada por Estados Unidos para fines ambientales", según la propia Embajada de Estados Unidos en Costa Rica. http://spanish.costarica.usembassy.gov/medio-ambiente.html (Consulta el 4 de febrero de 2016).

${ }^{3}$ Aunque no existe una evidencia puntual, la hipótesis es que iniciativas de este tipo estuvieron influenciadas por los efectos directos e indirectos de la crisis internacional de 1974-1975 y más tarde por las políticas ajuste estructural. Ambos factores pudieron marcar, en distintas perspectivas, la necesidad de resguardar la naturaleza como un recurso valioso de la nación. ${ }^{4}$ Esta Ley recibió medalla de oro del Future Policy Award 2010, entre otras cosas por el proceso participativo mediante el cual se elaboró.

${ }^{5}$ Para más detalles consultar el Resumen Nacional Ambiental, Costa Rica 2011, disponible en http://www.pnuma.org/publicaciones/Resumen\%20ambiental\%20nacional\%20Ver\%2023\%20Abril\%202012-\%20FINAL.pdf (Consulta el 4 de febrero de 2016)

${ }^{6}$ Silvia Rodríguez Cervantes, El despojo de la Riqueza biológica: de patrimonio de la humanidad a recurso bajo la soberanía del Estado (Heredia: EUNA, 2013).

${ }^{7}$ Gilbert Vargas Ulate, "Turismo y espacios naturales protegidos en Costa Rica: enfrentamiento o concertación", Ciencias Sociales 123-124 (2009): 53

${ }^{8}$ El MINAE se transformó en el Ministerio de Ambiente, Energía y Telecomunicaciones, MINAET en 2010 pero en 2013 volvió a ser denominado MINAE pues las telecomunicaciones pasaron a otra dependencia. Además, existe la propuesta de que este ministerio también asuma tareas relacionadas con aguas y mares.

${ }_{9}^{9}$ Artículo 8 de la Ley 6084. Ley del Servicio de Parques Nacionales (Colección de leyes y decretos: Año: 1977 Semestre: 2 Tomo: 2 Página: 473). "Dențro de los parques nacionales, queda prohibido a los visitantes: 1) Talar árboles y extraer
} 
una restricción casi absoluta sobre el acceso y uso de los recursos del área protegida, aspecto que dejaba por fuera cualquier posibilidad de explotación y cortaba de un tajo décadas de interacción socioecológica, con la consecuente pérdida de saberes bioculturales según la visión de Víctor Manuel Toledo. ${ }^{10}$ Por otro lado, esta orientación dada a la protección de los recursos parte del tiempo o escala biológica, dejando de lado las particularidades y necesidades del tiempo social, es decir, de las necesidades de la población que habita en las zonas sometidas a algún criterio de protección. En esencia el Ministro del MINAE o su representante dirige o supervisa el accionar de la mayoría de instancias creadas para la protección y promoción del ambiente. Esta práctica de control, o dicho de otra manera, esta falta de desconcentración de funciones, unida a la inexistencia de políticas reales de participación ciudadana, constituyen una de las principales trabas que mantiene al modelo de conservación en una situación de rigidez y de escaza innovación. Uno de los retos que se advierte para los próximos años es precisamente la desconcentración y el impulso a estrategias que proyecten la conservación desde un esquema integral de participación con actores sociales diversos como veremos en el siguiente apartado.

\section{Un modelo vertical de conservación}

Con el paso de los años, y luego de algunos aciertos y desaciertos, la Ley de Biodiversidad vino a establecer un esquema compacto de organización administrativa para el conjunto de las áreas protegidas, bajo la dirección del Sistema Nacional de Áreas de Conservación (SINAC). Mediante este "Sistema", el territorio nacional fue dividido en 11 áreas de conservación (10 continentales y una marina), cada una a cargo de un Consejo Regional. En la siguiente tabla se aprecian las principales instancias creadas entre 1995 y 1998.

\footnotetext{
plantas o cualquier otro tipo de productos forestales. 2) Cazar o capturar animales silvestres, recolectar o extraer cualquiera de sus productos o despojos. 3) Cazar tortugas mårinas de cualquier especie; recolectar o extraer sus huevos o cualquier otro producto o despojo. 4) Rayar, marcar, manchar o provocar cualquier tipo de daño o deterioro a las plantas, los equipos o las instalaciones. 5) Pescar deportiva, artesanal o industrialmente, salvo el caso previsto en el artículo diez. 6) Recolectar o extraer corales, conchas, rocas o cualquier otro producto o desecho del mar. 7) Recolectar o extraer rocas, minerales, fósiles o cualquier otro producto geológico. 8) Portar armas de fuego, arpones y cualquier otro instrumento que pueda ser usado para cacería. 9) Introducir animales o plantas exóticas. 10) Pastorear y abrevar ganado o criar abejas. 11) Provocar cualquier tipo de contaminación ambiental. 12) Extraer piedras, arenas, grava o productos semejantes. 13) Dar de comer o beber a los animales. 14) Construir líneas de conducción eléctrica o telefónica, acueductos o carreteras o vías férreas. 15) Realizar cualquier tipo de actividad comercial, agrícola o industrial".

10 Toledo, Víctor (2013). "El paradigma biocultural: "crisis ecológica, modernidad y culturas tradicionales". En: Sociedad y Ambiente, año 1, vol. 1, núm. 1, marzo-junio de 2013, ISSN en trámite, pp. 50-60.
} 
Tabla 1 - Estructura administrativa en materia ambiental en Costa Rica

\begin{tabular}{|l|l|}
\hline \multicolumn{1}{|c|}{ Ley Orgánica del Ambiente 1995 } & \multicolumn{1}{c|}{ Ley de Biodiversidad 1998 } \\
\hline Consejo Nacional Ambiental & $\begin{array}{l}\text { Comisión Nacional para la Gestión de la } \\
\text { Biodiversidad (CONAGEBIO) }\end{array}$ \\
\hline Secretaría-Técnica Nacional Ambiental (SETENA) ${ }^{11}$ & Oficina Técnica (apoyo a la Comisión) \\
\hline Consejos Regionales Ambientales & $\begin{array}{l}\text { Sistema Nacional de Áreas de Conservación } \\
\text { Consejo Nacional de Áreas de Conservación }\end{array}$ \\
\hline Tribunal Ambiental Administrativo & $\begin{array}{l}\text { Consejo Regional del Área de Conservación, } \\
\text { Comités científico-técnicos y consejos locales }\end{array}$ \\
\hline
\end{tabular}

Fuente: Elaboración propia a partir de las leyes citadas.

De acuerdo con la Ley de Biodiversidad, el CONAC es el máximo órgano en la definición de políticas ambientales. El artículo 25 señala que el CONAC es el encargado de la "ejecución de las estrategias y políticas tendientes a la consolidación y desarrollo del Sistema Nacional de Áreas de Conservación, y vigilar que se ejecuten". Lo interesante es que el Consejo Nacional de Áreas de Conservación lo integran el Ministro del Ambiente y Energía (quien lo preside), el Director Ejecutivo del SINAC (secretario), el director de la Oficina Técnica del CONAGEBIO, los directores de cada Área de Conservación y un representante de cada Consejo Regional de Área de Conservación. Hasta este punto, como se aprecia claramente, no hay participación de la sociedad civil, aspecto que se intenta resolver con la conformación de los consejos regionales. Según el artículo 29 de la Ley de Biodiversidad, cada Consejo Regional se "integrará mediante convocatoria pública, que realizará el representante regional del Sistema, a todas las organizaciones no gubernamentales y comunales interesadas, las municipalidades y las instituciones públicas presentes en el área".

Al definirse de esta manera la conformación de los consejos regionales, se excluye la representación de las distintas áreas protegidas y se favorece la integración de grupos política y económicamente poderosos en la definición de necesidades y en la aportación de criterios para políticas de corte ambiental. Y aunque la legislación prevé la creación de consejos locales, estos solo son posibles si ese grupo que controla el Consejo Regional lo considera necesario. De esta manera, el Sistema contribuye a "diluir" la protesta y las demandas puntuales de la gente que vive y convive con las áreas protegidas, aquellos que conocen sus necesidades. Sobre este punto volveremos más adelante cuando presentemos ejemplos concretos, donde la creación de áreas protegidas ha obviado totalmente la relación socioecológica que ha existido ahí por décadas y con ello deja de lado también los saberes tradicionales.

Sin embargo, las autoridades se han dado cuenta de la necesidad de involucrar a la población civil en el cuidado del ambiente y por ello han ideado estrategias que permitan su involucramiento en esferas ligadas a la vigilancia de los recursos, pero no así a la toma de

\footnotetext{
${ }^{11}$ Hasta ese momento denominada Comisión interinstitucional de control y evaluación de estudios de impacto ambiental, creada mediante el Decreto Ejecutivo No. 23783- MIRENEM, del 28 de octubre de 1994.

${ }^{12}$ Es potestad del Consejo Regional del Área de Conservación determinar la necesidad de establecer consejos locales. Así, la representación local o representación de base, ès opcional y está sujeta a lo que decida cada Consejo Regional dependiendo de la manera en que se constituya.
} 
decisiones. ${ }^{13}$ Por ello, al amparo en los mandatos de la Ley de Biodiversidad, se crea la Oficina de Sociedad Civil del Ministerio del Ambiente y Energía; entidad encargada de coordinar programas como "Bandera Ecológica, Guaria Ambiental, Comités de Vigilancia de los Recursos Naturales, Agenda Ambiental Costarricense y otros que la administración le asigne". ${ }^{14}$ El programa Bandera Azul Ecológica por ejemplo, está íntimamente relacionado con la limpieza de las playas, aspecto que a su vez responde a un criterio de calidad para los servicios que se ofertan a los turistas que llegan a las costas.

Gráfico 1 - Playas costarricenses premiadas por el Programa de Bandera Azul Ecológica 1996-2014

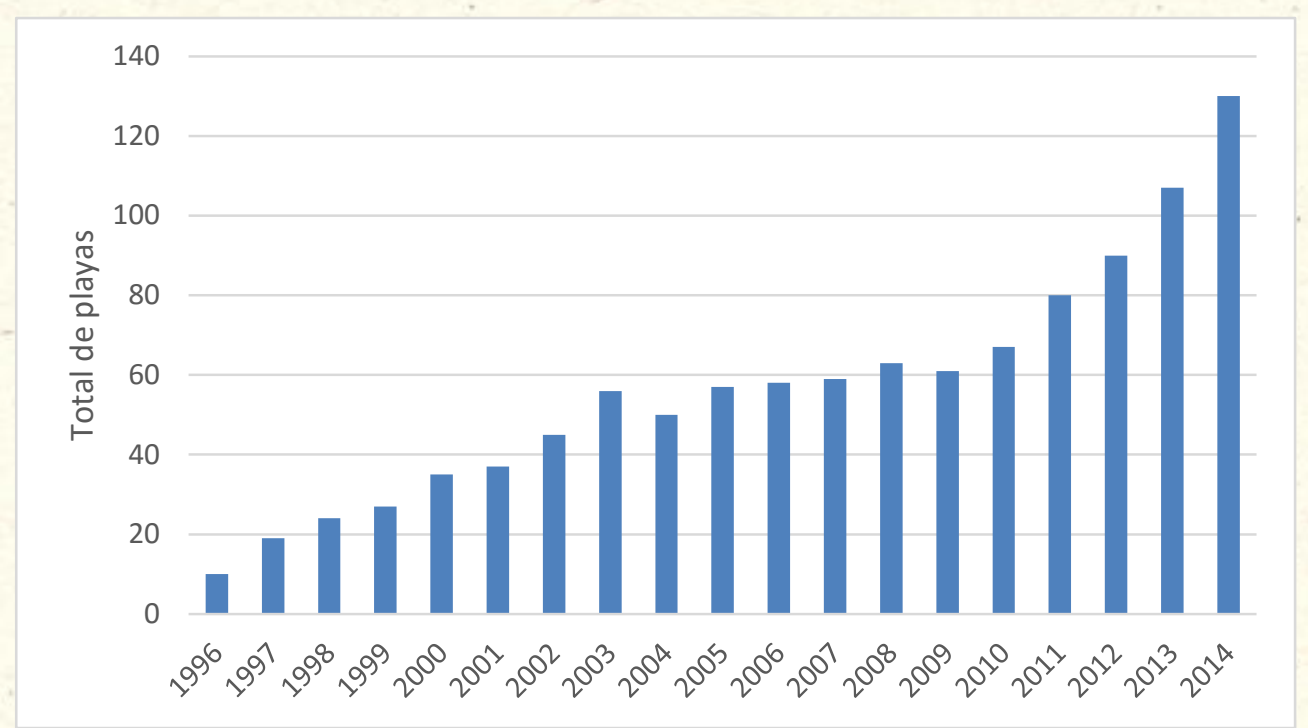

Fuente: Elaboración propia con base en datos del Estado de la Nación. Compendio estadístico Ambiental.

En particular, los Comités de Vigilancia de los Recursos Naturales (COVIRENAS) agrupados bajo una asociación denominada ASOCOVIRENAS, han desarrollado un papel protagónico en la formación y conducción de voluntariado que apoya las necesidades de las Áreas de Conservación, como el caso de las brigadas contra incendios. Otra iniciativa que ha logrado una significativa participación civil son las Asociaciones Administradoras de Sistemas de Acueductos y Alcantarillados Sanitarios (ASADAS) las cuales funcionan con especial regularidad en las zonas rurales y casi por completo atendiendo temas relacionados con el suministro de agua potable.

Aunado a esto y con el fin de contribuir en la etapa preventiva de los daños al ambiente, el MINAE también creo la Dirección de Gestión de Calidad Ambiental (DIGECA) en el año 2002. Desde esta dirección șe intenta:

\footnotetext{
${ }^{13}$ Chinchilla Morales, Marcos (2007). "Gestión medio ambiental y participación social: la política social construida desde las comunidades". Chile, Revista Perspectivas \# 18. Departamento de Trabajo Social,

Universidad Católica Silva Enríquez, p7.

${ }^{14}$ Ministerio de Ambiente y Energía, DECRETO № 27485. San José, Costa Rica, 1998.
} 
Promover la mejoría en la calidad ambiental y la prevención de la contaminación mediante el diseño e implementación de herramientas e instrumentos técnicos y jurídicos de gestión ambiental que impulsen la producción y el consumo sostenible en los diversos sectores de la sociedad, contribuyendo así a alcanzar el desarrollo sostenible en el país". ${ }^{15}$

Ese objetivo de DIGECA se complementa desde el MINAE con la puesta en marcha de las denominadas Agenda azul, Agenda verde (que incluye una sub-agenda marina), Agenda café y Agenda energética. Adicionalmente se creó el Sistema de Reconocimiento Ambiental (SIREA) que es "el primer mecanismo oficial orientado a reconocer públicamente a aquellas organizaciones, empresas o comunidades que están aportando a la calidad ambiental del país, a partir de proyectos o prácticas productivas amigables con el ambiente". ${ }^{16}$ Así el SIREA trabaja en reconocimientos como Emprendedurismo Ambiental, Producción más Limpia $(\mathrm{P}+\mathrm{L})$, Ecoeficiencia, Responsabilidad Social, Programa Bandera Azul Ecológica y Sello sanitario de calidad. ${ }^{17}$ Para el desarrollo de esa labor el SIREA se nutre de información proveniente del Centro Nacional de Información Geoambiental (CENIGA) creado en 2001 y del Sistema Nacional de Información Ambiental (SINIA), ambas pertenecientes al MINAE.

Como se desprende de lo dicho hasta aquí, es indudable que se han logrado importantes avances en la gestión de la calidad ambiental y en la preservación de los recursos naturales en Costa Rica. También es cierto que existe una prolija legislación en materia ambiental general y específica en temas como aguas, biodiversidad, vida silvestre, bosques, suelos, quemas, minería y contaminación. Sin embargo, también es cierto que el esquema vertical que opera en el modelo de conservación no potencia eficientemente la participación ciudadana y por el contrario la restringe a espacios de supervisión y vigilancia en el uso de los recursos. Tampoco posibilita la participación y representación de las diversas zonas protegidas en el nivel de toma de decisiones pues el CONAC constituye un espacio de participación reducido. ${ }^{18}$

Es particularmente inquietante que al realizar este trabajo no se encuentren estudios que analicen la eficiencia o ineficiencia de este esquema de conservación. Eso nos lleva a pensar que efectivamente el esquema funciona ante los ojos de quienes lo conocen e impulsan, y evidentemente pasa desapercibido para una gran cantidad de personas que no están familiarizadas con el tema. $Y$ esto ocurre, en nuestro criterio, porque no hay una alternativa al modelo de conservación museístico que opera en el país.

El esquema centralizado de administración de las áreas silvestres protegidas se sustenta en un concepto de control absoluto y está respaldado por una legislación punitiva. Los planes de desarrollo nacional y las políticas de participación ciudadana abundan en el papel, y no son ajenas a la temática ambiental, pero los mecanismos para ponerlas en práctica aún no existen o no hay recursos para hacerlo pues la inversión en este campo es reducida $(0.35 \% \text { del PIB en } 2014)^{19}$ a pesar de que aporta de manera significativa al PIB nacional como veremos ahora. No obstante esos inconvenientes, y-aunque no entraremos a

\footnotetext{
${ }^{15}$ MINAE, DIGECA. http://www.digeca.go.cr (consulta 9-febrero-2016).

${ }^{16}$ MINAE, SIREA. http://www. sirea.minae.go.cr (consulta 9-febrero-2016).

17 Íbid.

${ }^{18}$ Han tenido más espacio entidades como la Fundación de Parques Nacionales creada desde finales de los años 1970 con la participación de personas como Mario Boza y Álvaro Ugalde, desde la cual se han dedicado a buscar fondos que permitan comprar tierras e impulsar la conservación en espacios privados y públicos estatales.

${ }^{19}$ Estado de la Nación. Compendio Estadístico Am̄biental. Disponible en:

www.canapep.com/wp-content/uploads/2015/12/Compendio-Legal-Ambiental-2010.pdf Consulta (1-marzo-2016)
} 
analizar ese tema, hay algunas experiencias de gobernanza bajo el esquema de co-manejo que han obtenido buenos resultados y en otras que no han corrido la misma suerte. ${ }^{20}$

\section{Conservación y políticas nacionales en conflicto}

De manera sucinta y seguros de que aún quedan aristas por tratar, hasta aquí se hizo un acercamiento al complejo tema de la administración y la conservación ambiental en Costa Rica. A partir de ahora nos centraremos en determinar las contradicciones o problemas que se advierten de ese modelo de conservación y de otras políticas que aportan a esa complejidad. En particular intentaremos mostrar como la creación de áreas protegidas y de corredores biológicos entran en choque con la política nacional de asignación de tierras generando un fuerte desequilibrio y provocando mayor tensión ambiental en el sentido propuesto por Mauricio Folqui. ${ }^{21}$ A esto le sumaremos, a manera de ejemplo, los problemas introducidos por la política en cuanto a permisos emitidos para explotación de recursos.

Como se aprecia en el mapa 1, el conjunto de áreas protegidas creado en Costa Rica se encuentra disperso por el territorio nacional, con especial presencia en los sectores fronterizos y costeros. Esta distribución obedece a diversos factores, entre ellos la facilidad con que el Estado puede adquirir terrenos que están en zonas marginales y muchas veces en manos de campesinos. ${ }^{22}$

Basta con estudios que determinen la necesidad de proteger una especie animal o vegetal, la protección de un acuífero o simplemente el resguardo de un área por su belleza escénica. Estos y otros argumentos son suficientes para que el Estado impulse, desde sus instancias correspondientes, las políticas para la adquisición de tierras o incluso desalojos con el fin de resguardar esos bienes naturales. Entre los argumentos que usualmente se exponen es que la protección de un área en específico vendrá a ofrecer una serie de servicios ecosistémicos ${ }^{23}$ que contribuirán a la economía del lugar, así como al desarrollo de la economía regional.

\footnotetext{
${ }^{20}$ En 2014 por ejemplo, debido a problemas administrativos, el MINAE se vio obligado a emitir el decreto MINAE N². 262014 en el cual "Se instruye al Consejo Nacional de Áreas de Conservación, para que, en un plazo de hasta seis meses, en conjunto con los representantes de las organizaciones de la comunidad de Cahuita vinculadas al comanejo, se establezcan las condiciones técnicas y legales necesarias para que el modelo de Gobernanza de comanejo en el Parque Nacional Cahuita continúe operando..."

${ }^{21}$ Folchi D, Mauricio (2001). "Conflictos de contenido ambiental y ecologismo de los pobres: no siempre pobres, ni siempre ecologistas". En Ecología Política. Cuadernos de debate internacional, N. ${ }^{\circ}$ 22. España, Icaria editorial.

${ }^{22}$ Está claro que en el Valle Central el Estado no podría actuar con tanta ligereza para crear áreas protegidas pues implicaría lidiar con procesos judiciales complejos y en muchos casos demasiado onerosos para el erario público.

${ }^{23}$ Por ejemplo, en la creación del Refugio de Vida Silvestre Caño Negro se fundamentó que ese espacio ofrecería los siguientes servicios ecosistémicos: Alimento, artesanías, belleza escénica, biodiversidad, comercio, educación ambiental, herencia, identidad cultural, investigación, producción agropecuaria, purificación del aire, recarga hídrica, recreación, regulación del clima, transporte y turismo. (MINAE, SINAC, http://www.sinac.go.cr/AC/ACAHN/RVSCanoNegro (consulta 12noviembre-2015).
} 
Mapa 1 - Áreas silvestres protegidas de Costa Rica.

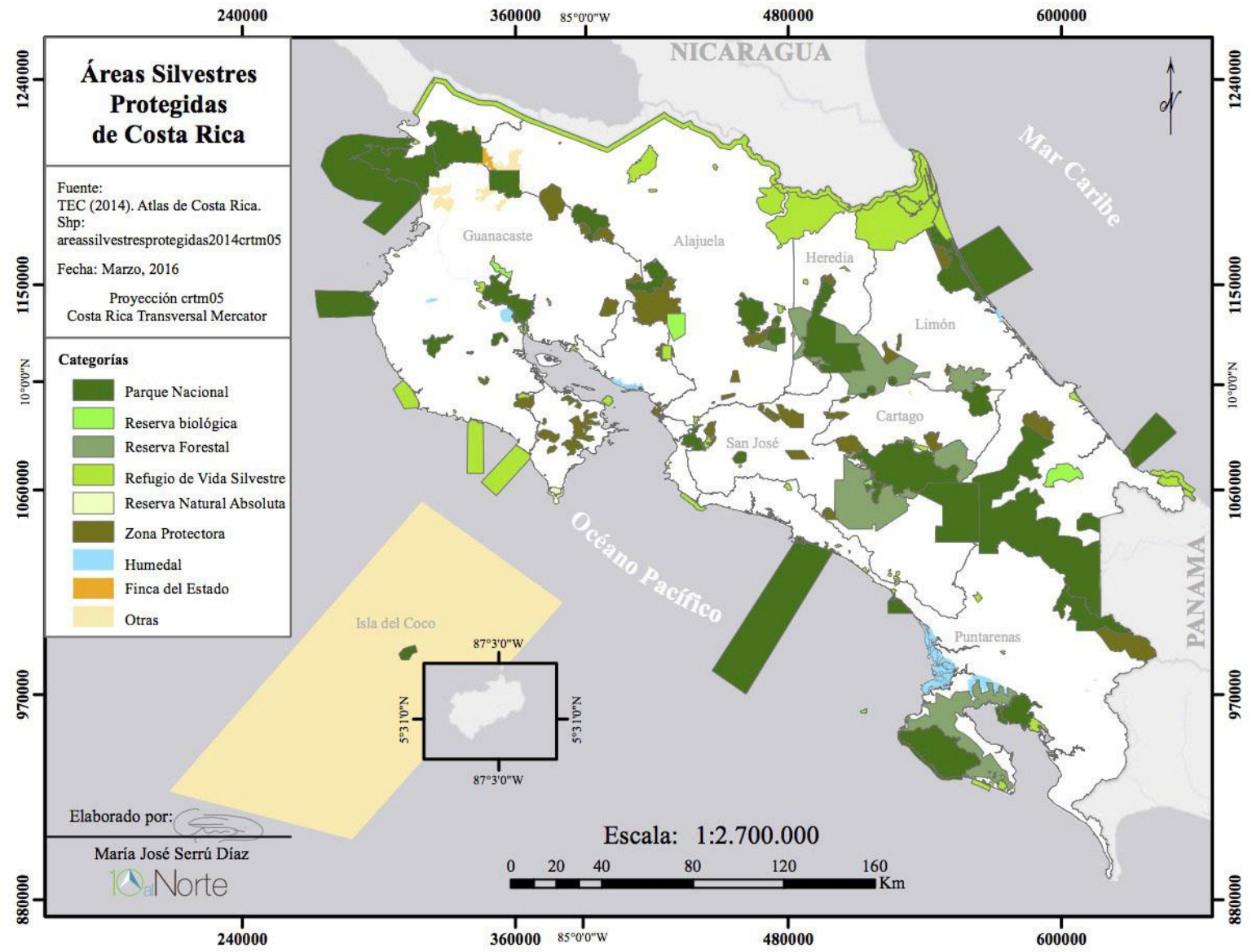

Fuente base: MINAE-SINAC.

Lamentablemente quienes aprovechan esos servicios son, en la mayoría de los casos, actores sociales ajenos al área de conservación, como los tours operadores, transportistas y cadenas hoteleras, mientras que los vecinos de las zonas protegidas reciben un beneficio marginal. Por ejemplo, a lugares como el Refugio de Vida Silvestre Caño Negro, ubicado en el Área de Conservación Arenal Huetar Norte (ACAHN) llegan turistas que contratan algún servicio de transporte acuático para hacer un recorrido por el río Frío o por el sistema de lagunas que existe ahí y eventualmente pagan por consumo en algún pequeño restaurante, pero aunque existen opciones de hospedaje local, estos turistas se hospedan a unos 80 kilómetros en el sector de la Fortuna de San Carlos, polo turístico donde hay grandes hoteles y operadores quienes realmente se aprovechan de las betlezas naturales de Caño Negro.

Ahora bien, como ya ha sido demostrado por la ecología del paisaje, esa fragmentación o islas de conservación no facilitan la migración e interacción de especies entre distintos espacios. Por ello, la solución se ha centrado en la conformación de los denominados corredores biológicos. Aunque Costa Rica estuvo involucrada desde 1999 con la iniciativa del Corredor Biológico Mesoamericano; fue hasta 2006 que definió su Programa Nacional de Corredores Biológicos (PNCB). Al 2010 Costa Rica ya contaba con 37 corredores biológicos en todo el territorio, algunos de ellos transfronterizos como en el caso 
del "Corredor Biológico Binacional de los Humedales Nicaragua-Costa Rica" y la denominada Reserva de Biosfera Agua y Paz, creada desde el año $2007 .{ }^{24}$

Mapa 2 - Corredores biológicos en Costa Rica al 2010.

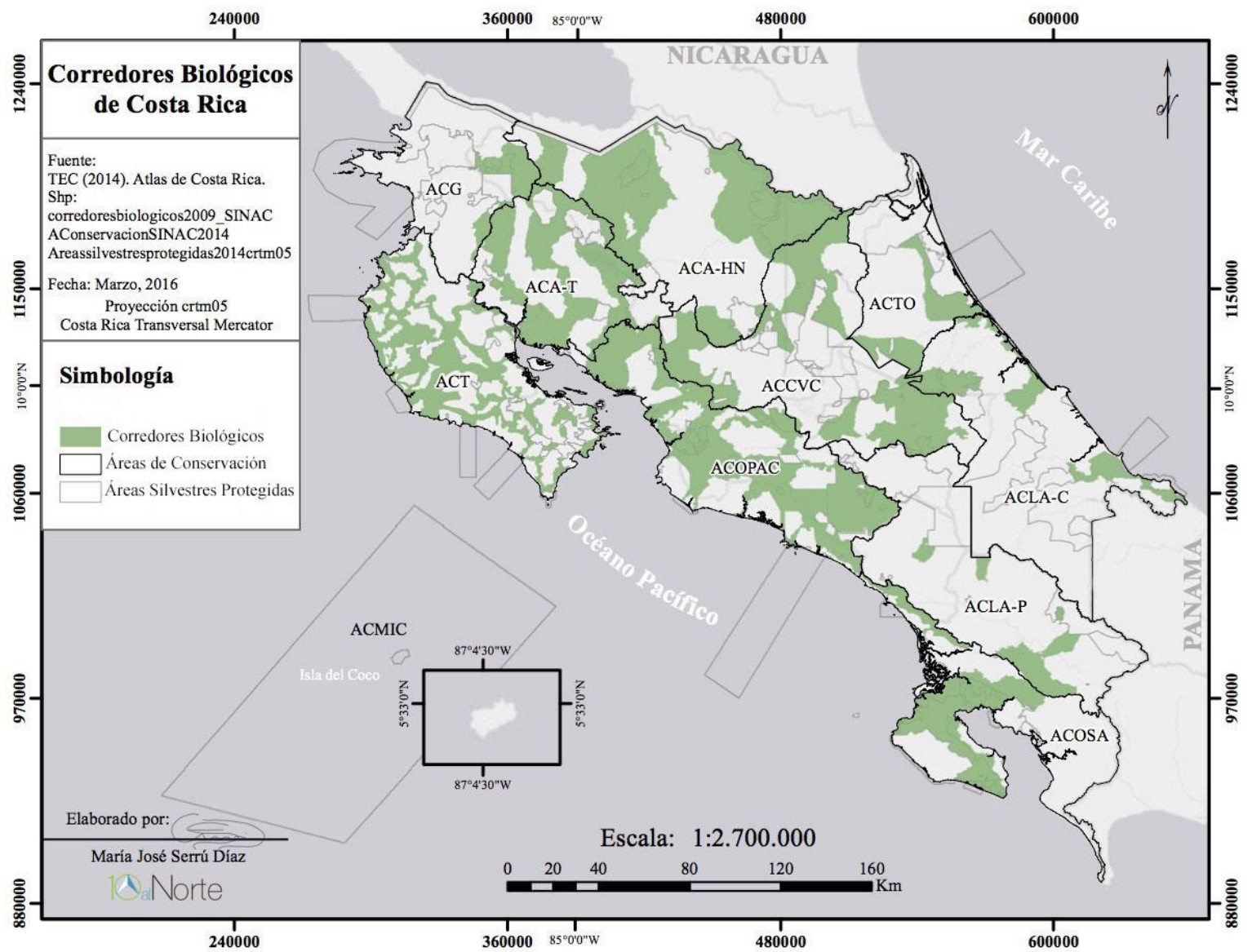

Fuente base: MINAE-SINAC

Como se aprecia en el mapa anterior, la mayoría de áreas silvestres protegidas se encuentra interconectada con otras mediante una extensa red de corredores biológicos lo cual constituye un avance sustantivo pues contribuye a mantener en cierta forma dinámica natural de los ecosistemas. Sin embargo, la vigilancia, monitoreo y control de las actividades humanas que tienen lugar en los corredores biológicos constituye uno de los principales problemas que enfrenta el programa. De un lado se señala la escasez de recurso humano calificado en temas ambientales y de conservación, y del otro un problema financiero debido a una reducida inversión como se indicó anteriormente. A esto se puede sumar la falta de información para decir que esos tres factores se han convertido en una traba incluso para las iniciativas de gobernanza ambiental que se han impulsado en los últimos años. Pero el problema que queremos evidenciar no es la falta de recursos o de supervisión de los corredores biológicos, sino el que aparece al examinar la congruencia de estas políticas de conservación con la política nacional de asignación de tierras a los campesinos. El Instituto Costarricense de Tierras y Colonización (ITCO ${ }^{25}$ fue creado en octubre de 1961 con el fin de

\footnotetext{
${ }^{24}$ Esta Reserva de Biosfera constituye una iniciativa multisectorial y está orientada, según sus promotores, a convertirse en un "Modelo de Desarrollo Sostenible con enfoque de Cambio Climático".

${ }^{25}$ El ITCO fue transformado luego en Instituto de Desarrollo Agrario (IDA) y de manera más reciente en Instituto Nacional de Desarrollo Rural (INDER). .
} 
enfrentar el problema de acceso a la tierra debido al agotamiento de la frontera agrícola. En el artículo 1 de la Ley de creación del ITCO se establecía como su primer objetivo:

Determinar que la propiedad de la tierra se debe promover para el aumento gradual de su productividad y para una justa distribución de su producto, elevando la condición social del campesino y haciéndolo partícipe consciente del desarrollo económico-social de la Nación. ${ }^{26}$

Es oportuno destacar también que esta necesidad y el concepto de "justicia social" que se trasluce de ese objetivo, se presenta en un contexto donde las demandas sociales eran cada vez más fuertes y en la región centroamericana hacía eco la revolución cubana ocurrida tan solo 2 años antes. ${ }^{27}$ Aunque no vamos a entrar en el análisis de ese fenómeno, si podría asumirse como hipótesis que la distribución de tierras a campesinos también llegó a jugar como una estrategia de contención de la demanda social.

Por lo demás, si se analiza la metodología que utilizaba el ITCO y el IDA para la asignación de tierras en la década de 1970 y 1980 por ejemplo, nos damos cuenta de que esta comportaba una estrategia de desmovilización pues cada asentamiento campesino se constituía con gente llevada de las más diversas zonas del país. Al hacer esto se lograba romper cualquier posibilidad de protesta y, aunque siempre existía la posibilidad de reorganización al interno de los asentamientos, la experiencia les fue dictando a los políticos que ese era el camino correcto y que esto también podía constituirse en un mercado de votos.

Mapa 3 - Asentamientos campesinos creados por el IDA al 2008.

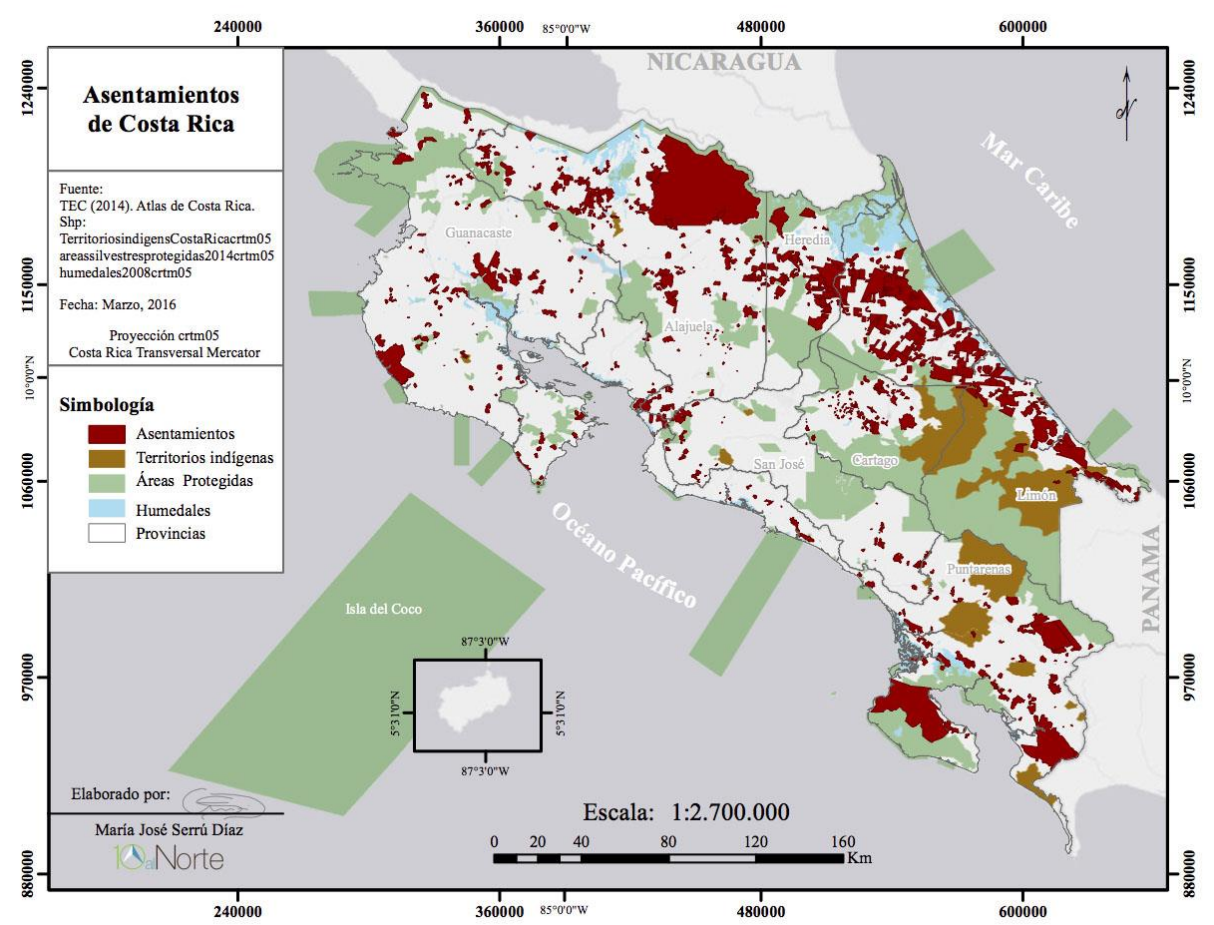

Fuente base: Instituto de Desarrollo Agrario (IDA), 2008.

\footnotetext{
${ }^{26}$ Ley de creación del Instituto de Tierras y Colonización, Ley de Tierras y Colonización, 2825 del 4 de octubre de 1961.

${ }_{27}$ También es oportuno recordar que en 1971 Costa Rica firma el Convenio de la Alianza para el Progreso de los Estados Unidos y en su artículo II se establece claramente que el gobierno de Costa Rica "[...] dará todas las oportunidades y facilidades a los representantes del gobierno de lōs Estados Unidos de América para que observen y revisen los programas y actividades que se conduzcan de acuerdo con este Convenio [..]".
} 
Ahora bien, al observar la ubicación de los asentamientos campesinos creados por el ITCO-IDA se constata que muchos de ellos fueron creados en las proximidades o incluso en las zonas de amortiguamiento de las áreas protegidas y en esencia la mayoría está dentro de los corredores biológicos. Ubicar a campesinos en estas tierras provoca directamente una mayor presión sobre los recursos naturales, presión que se hace extensiva a los recursos ubicados en las zonas protegidas cercanas como ocurre en con el Refugio de Vida Silvestre Caño Negro que veremos más adelante. En cumplimiento de lo establecido en el artículo 1 de la creación del ITCO se esperaría que un campesino que recibe tierra "la ponga a producir" por su bienestar y el de la Nación. Por lo tanto, resulta lógico pensar que este campesino o agricultor debe abrir campos de cultivo y áreas de pastos para obtener su sustento y el de su familia, prácticas que en la mayoría de los casos riñen con los criterios de conservación.

Esta situación no ha pasado desapercibida por completo para el Estado y por ello desde 2004 el SINAC viene impulsando el proyecto GRUAS II: "Propuesta de Ordenamiento Territorial para la Conservación de Biodiversidad en Costa Rica". Desde este programa se busca

\begin{abstract}
delimitar las áreas de mayor valor para la conservación, conocer su estado actual de alteración e identificar los vacíos que existan en cada uno de esos campos. Pretende mantener muestras representativas de la riqueza natural del país ya sea bajo la modalidad de áreas silvestres protegidas o bajo iniciativas privadas de conservación, relacionando éstas con actividades productivas de relevancia nacional o local que sean compatibles con la conservación. En síntesis, GRUAS II representa una herramienta que acerca el esfuerzo nacional de conservación, al desarrollo social y económico del país." ${ }^{8}$
\end{abstract}

De igual manera se pueden citar una serie de trabajos y estrategias impulsadas desde el Estado y de sus instituciones de cara a mitigar el daño ambiental y mejorar la administración de los recursos naturales de manera que estas contradicciones entre las políticas públicas no afecten el ambiente. En este sentido pueden citarse las siguientes Estrategias Nacionales: para la Conservación y Uso de la Biodiversidad (2000), de Investigación en Recursos Naturales y Culturales (2000), para la Conservación y el Manejo de la Vida Silvestre (2003), del Manejo del Fuego en Costa Rica (2006-2011), para la Conservación y Uso Racional de los Humedales (2005), para la Educación Ambiental del SINAC (2005-2010), para el Control de la Tala llegal (2002) y la Agenda para las Áreas Silvestres Protegidas Administradas por el SINAC (2003). ${ }^{29}$ También se ha impulsado otra iniciativa orientada a mejorar las condiciones forestales y de protección de recursos hídricos denominada Fondo Nacional de Financiamiento Forestal (FONAFIFO). Mediante este fondo se promueve el Pago por Servicios Ambientales (PSA) dedicados a reforestación (sobresale el pago para las especies nativas), regeneración natural, protección (incluye protección en

\footnotetext{
${ }^{28}$ MINAE (2006). "Proyecto Gruas II. Propuesta de ordenamiento territorial para la conservación de la biodiversidad en Costa Rica". San José, Costa Rica, p 1.

Este proyecto tiene sus antecedentes en el proyecto de "Macrotipos de Vegetación" elaborado por Wilberth Herrera y Luís Diego Gómez en 1986, al cual se le bautizó con el nombre de GRUAS y actualmente se conoce como GRUAS I.

${ }^{29}$ SINAC, Proyecto GRUAS II (2007). Análisis de vacíos de conservación en Costa Rica: Vol II. Análisis de Vacíos en la Representatividad e Integridad de la Biodiversidađ de los sistemas de aguas continentales. San José, Costa Rica.

Asociación Conservación de la Naturaleza, p 3.
} 
vacíos de conservación), protección de recurso hídrico, manejo de bosque y sistema agroforestal.

Gráfico 2 - Total de hectáreas incorporadas por año al Pago de Servicios Ambientales entre 1997 y 2014 , según categorías

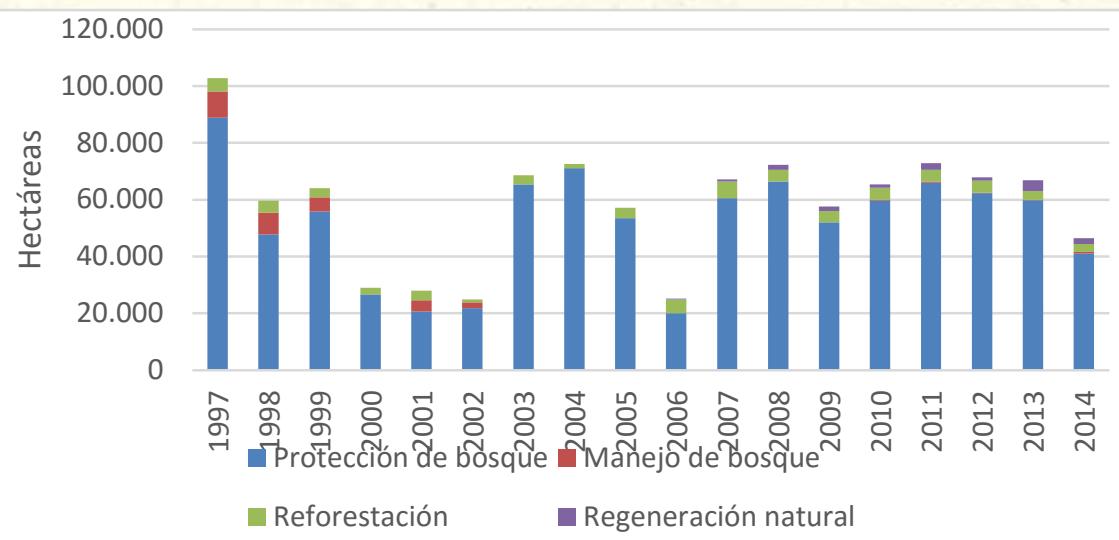

Fuente: Elaboración propia con base en datos del Estado de la Nación. Compendio estadístico Ambiental. Este gráfico no incluye el PSA en áreas indígenas ni los destinados a protección de recurso hídrico.

Como se visualiza en el gráfico anterior, el PSA involucra una media de 40 mil hectáreas anuales que funcionan bajo contratos quinquenales de conservación. Mediante este servicio, cualquier propietario puede presentar solicitud ante el FONAFIFO y recibir un incentivo a cambio de reforestar o proteger bosques existentes; por ejemplo, para la inversión de PSA de 2015 se fijó entre 1180 y 2100 dólares por hectárea, desembolsables en 5 años. ${ }^{30}$ Además, muchos proyectos de conservación en el país se desarrollan gracias a la cooperación internacional que entre 2009 y 2014 aportó más de 95 millones de dólares y de 13 millones de euros. ${ }^{31}$

Este panorama donde las políticas emanadas del Estado entran en fuerte contradicción y terminan pasando factura al ambiente, se complementa con situaciones desafortunadas como concesiones y permisos que han marcado de alguna forma la organización ambientalista costarricense y han desatado fuertes luchas. Quizás por sus repercusiones sociales, políticas e incluso educativas, uno de los episodios más significativos lo constituye la lucha contra la Aluminum Company of America (ALCOA) en 1970 con quien el gobierno intentó negociar un contrato ley para explorar yacimientos de bauxita en el sur del país. La aprobación de ese contrato en la Asamblea Legislativa de Costa Rica fue el detonante que movilizó a diversos actores sociales, entre ellos la federación de estudiantes de la Universidad de Costa Rica, sindicatos y otras agrupaciones. Luego de fuertes enfrentamientos y arresto de manifestantes en diversas partes del país, el Estado se vio obligado a dar marcha atrás a ese proyecto. Aunque ALCOA tuvo lugar en los años previos al bum de los parques nacionales, para muchos esa lucha marcó el inicio del ecologismo en Costa Rica. Para efectos de nuestra lectura, y a pesar de que esto se da en

\footnotetext{
${ }^{30}$ Costa Rica. Diario Oficial La Gaceta. Año CXXXVII, Número 143. San José Costa Rica, viernes 24 de julio de 2015. En el caso de PSA de un sistema agroforestal, el monto se estima por cada árbol reforestado y de igual manera se privilegian las especies nativas.

${ }^{31}$ Ulate, Chacón, Ricardo (consultor). Programa dē la Naciones Unidas para el Medio Ambiente (PNUMA). "Resumen Ambiental Nacional Costa Rịca 2011", Anexo III, pp 38-40.
} 
un contexto de lucha política32, entendemos lo sucedido con ALCOA como una manifestación de lo que ocurría en ese momento con las iniciativas relacionadas con el ambiente: no existía una visión clara de la conservación y por ello no resultaba disonante la explotación de un recurso mineral aunque implicara un coste ambiental.

Gráfico 4 - Total de acciones colectivas em materia ambiental registradas entre 1994 y 2014

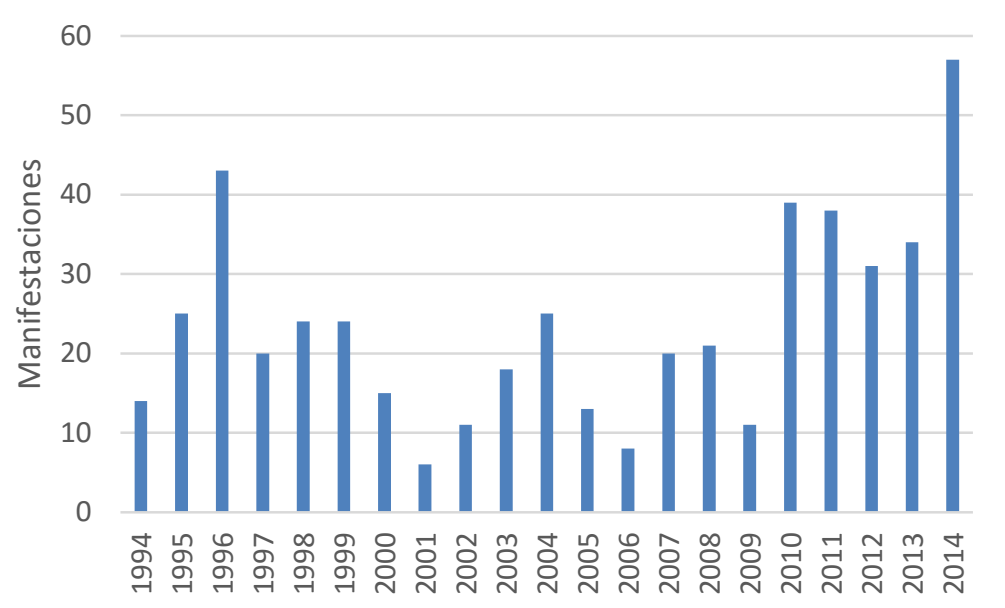

Fuente: Elaboración propia con base en datos del Estado de la Nación. Compendio estadístico Ambiental.

Sin embargo, si resulta alarmante, reprochable y absolutamente contradictorio lo ocurrido en 2008 cuando se autoriza una concesión minera a cielo abierto a la empresa Infinito Gold Ltd, mediante la cual se pretendía extraer un millón de onzas de oro en la zona limítrofe con Nicaragua. ${ }^{33}$ La indignación de amplios sectores de la sociedad costarricense, entre ellos grupos ecologistas y ambientalistas, pero también de universidades y sindicatos entre otros, logró detener el proyecto que amenazaba no solo el frágil equilibrio ecológico en la zona sino también la calidad de las aguas cercanas, en particular del río San Juan. Aunque no en esa escala, varios proyectos impulsados por instituciones como el Instituto Costarricense de Electricidad (ICE) también han recibido fuerte oposición por considerarse que son perjudiciales para el ambiente. Pero además, estas manifestaciones ya no son casos aislados sino que forman parte de una dinámica de denuncia que se vuelve cada vez más evidente como se aprecia en el siguiente gráfico.

\footnotetext{
32 Barahona, Francisco (2015). "A 45 años de ALCOA". Costa Rica, Semanario Universidad, sección de opinión, mayo. Disponible en http://semanariouniversidad.ucr.cr/opinion/45-anos-de-alcoa/ Consulta (4-marzo-2016).

${ }_{33}$ Para conocer más sobre este tema pueden conšultar el estudio publicado por la Asociación Interamericana para la Defensa del Ambiente (AIDA), disponible en www.apreflofas.or.cr/mineria_crucitas/analisis_de_crucitas.pdf
} 
Gráfico 5 - Total de qùejas tramitadas por el SINAC en relación con recursos naturales entre 2004 y 2014

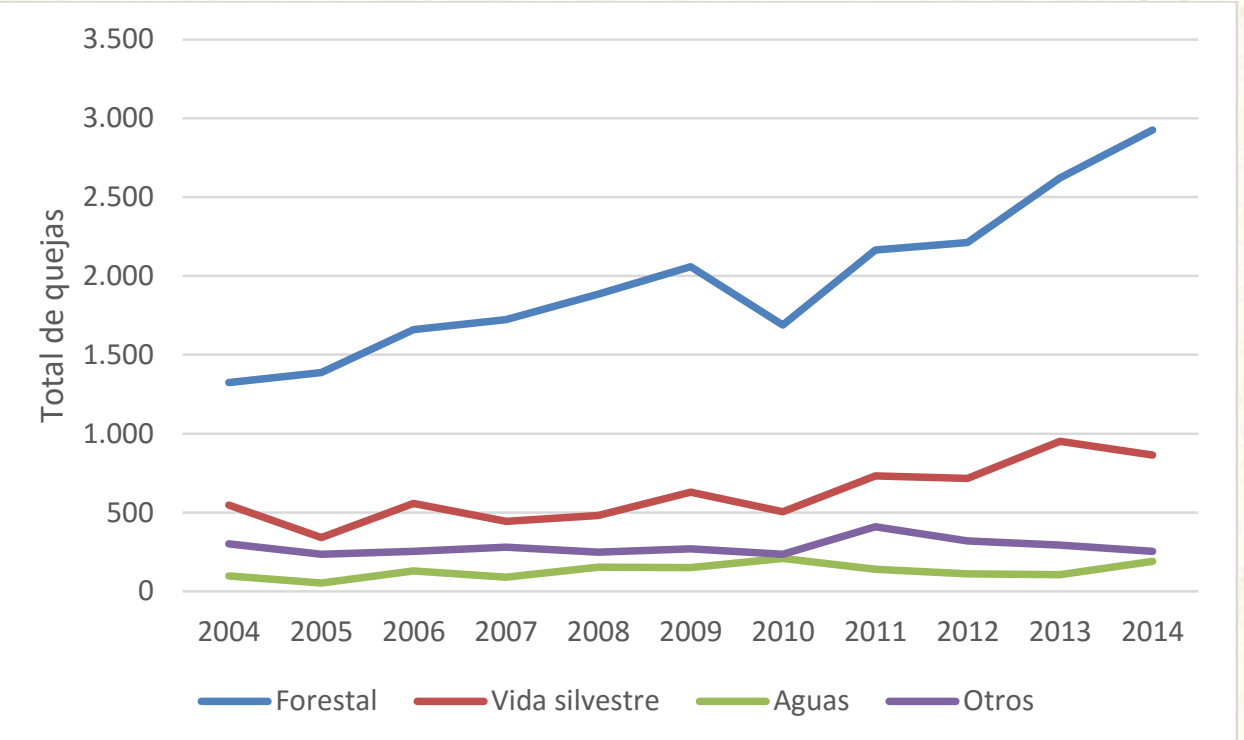

Fuente: Elaboración propia con base en datos del Estado de la Nación. Compendio estadístico Ambiental.

Esta dinámica de denuncia ha contribuido a que el Tribunal Ambiental Administrativo, creado mediante la Ley Orgánica del Ambiente en 1995, desarrolle una importante labor en la resolución de conflictos. Asimismo, los datos reflejan que las denuncias por daños ocasionados en áreas protegidas son cada vez más comunes lo que refleja el involucramiento y el papel vigilante que desarrollan algunas comunidades y ONG vinculadas a la protección ambiental.

Gráfico 6 - Total de casos procesados por el Tribunal Ambiental Administrativo entre 2004 y 2014

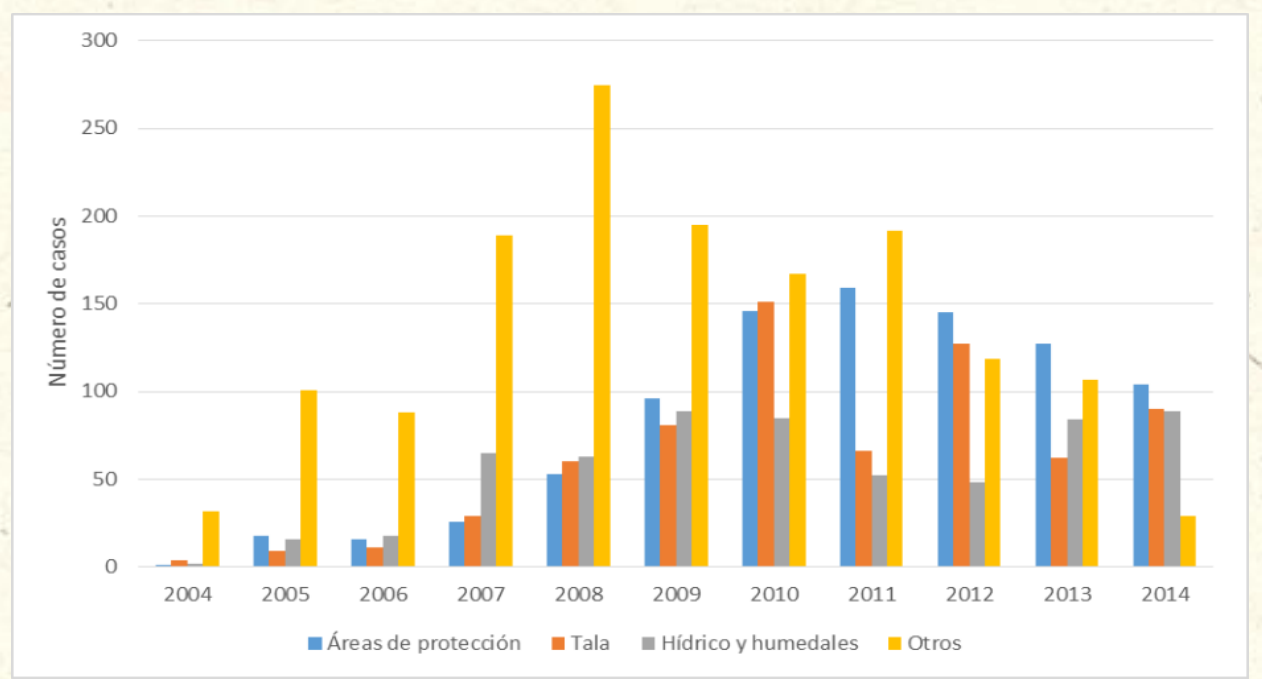

Fuente: Elaboración del autor con base en datos del Tribunal Ambiental Administrativo.

\section{La conservación y tensión ambiental en dos casos de estudio}

En este apartado vamos a comentar de manera breve las principales situaciones de tensión ambiental que hemos encontrado en dos escenarios sometidos a investigación en los últimos años, el caso de Santa María de Dota con la presencia de un parque nacional y 
una reserva forestal y el de Caño Negro de Los Chiles donde se ubica un refugio de vida silvestre.

Dota es un cantón ubicado en al sur de San José. La abundancia de recursos forestales propició la incorporación de algunas compañías madereras y grupos de carboneros que se internaron en los bosques para explotar la madera de roble y encino. Esto provocó diferentes reacciones a nivel local y nacional, y como consecuencia se impulsó en 1945 la creación de un Parque Nacional paralelo a la Carretera Interamericana Sur34, pero la situación no se contuvo. En 1964, para contrarrestar los efectos de la actividad carbonera, el ITCO propuso reforestar algunas zonas de la Reserva de Río Macho cercanas a la Carretera Interamericana Sur pero la idea no se concretó ${ }^{35}$ y por el contrario la actividad carbonera se consolidó como el centro de diferentes críticas. Existe una visión popular que culpabiliza a los carboneros por la intensa deforestación en los robledales de altura, pero la mayoría de ellos opina que esta activad no es la responsable de la intensa deforestación en la segunda mitad del siglo XX. Un antiguo carbonero de la zona argumentó: "nosotros andábamos por todo lado, no estaba eso de forestales, no había problema. Acá no se deforestó en el tiempo del carbón ino! Acá esto se deforestó muy anteriormente." 36

Al igual que la producción de carbón, la explotación de madera se desarrolló de una forma intensiva durante la mayor parte de la segunda mitad del siglo XX. A mediados de la década de 1970 llegó al cantón la compañía maderera STABAPARI la cual se dedicó a extraer roble y exportarlo a Europa para fabricar barriles de añejamiento para licores. Contrario a la producción de carbón, la extracción de madera si provocó la organización comunal dada la preocupación del deterioro de las cuencas hidrográficas y las nacientes de agua comunales.

El movimiento local provino desde el entorno escolar y municipal, que se convirtieron en foros de discusión sobre las consecuencias de la deforestación. Sin embargo, las quejas planteadas se canalizaron por la vía tributaria, dado que no se pagaba ningún impuesto por la madera extraída. Como respuesta a esa situación, en 1974 la Municipalidad de Dota aprobó un impuesto por cada camión que transitara cargado de madera. ${ }^{37}$ Pero la oposición a la compañía maderera también desencadenó la movilización local lo cual llevó a la creación de la Reserva Forestal Los Santos lo cual marcó el inicio de la formación de diferentes zonas protegidas que caracterizan a Dota hoy en día.

En 1974 se realizaron varias denuncias por deforestación en las nacientes del río Parrita y en las zonas de captación de aguas comunales. Como consecuencia, desde el seno del municipio se propuso crear un parque nacional que protegiera el recurso maderable e hídrico y se consultó al Ministerio de Agricultura y Ganadería cuáles eran los lineamientos a seguir para que "el área de las nacientes del río Parrita se declare Parque Nacional, en vista de la tala de árboles que están produciendo. Se debe empezar a trabajar muy pronto, ya que si continúa la situación tan crítica, antes de 20 años el río Parrita desaparecerá". ${ }^{38}$

\footnotetext{
34 ITCO, Memoria Anual de 1963, (San José, Costa Rica: Instituto de Tierras y Colonización, 1963), 40-41. El Parque Nacional que se menciona se creó en 1945 en los siguientes términos: "Por decreto No 197 del 29 de agosto de 1945, se declaró Parque Nacional la faja de robledales a ambos lados de la Carretera Interamericana [Sur]". Los paréntesis cuadrados son del autor.

35 ITCO, Memoria Anual de 1964 (San José, Costa Rica: Instituto de Tierras y Colonización, 1963), 30.

${ }^{36}$ Entrevista con Juan Bautista (Tista) Quirós, Jardín de Dota, viernes 29 de enero de 2010.

${ }^{37}$ Archivo Nacional de Costa Rica (ANCR), Fondo Municipal, Sig. 16275, 1974, FF. 259-260.

${ }^{38}$ ANCR, Fondo Municipal, Sig. 16275, 1974, F. 134.
} 
Esta y otras medidas sirvieron para que la compañía maderera abandonara la región en 1978 y se declarara la Reserva Forestal Los Santos con 62700 hectáreas. Pero, aunque esa reserva sirvió a los objetivos de algunos líderes comunales que querían proteger los bosques, otros encontraron en ella una limitante para desarrollar sus actividades agrícolas. Como consecuencia, en octubre de 1978 la Municipalidad envió un comunicado al Ministro de Agricultura para solicitar la reducción de los límites de la reserva, pero el Estado no colaboró y se continuó con las mismas proporciones. ${ }^{39}$ Posteriormente, en la década de 1990 se solicitó ampliar el área de construcción habitacional de la reserva, bajo el argumento de que muchos de sus propietarios no podrían heredar tierras a sus hijos, ni construir en sus propiedades, aspecto que complicaba la situación socioeconómica de estos territorios. ${ }^{40}$ Lo cierto es que no se redujeron los límites de la reserva y por el contrario se consolidaron otras áreas protegidas. Por ejemplo, en 1994 se concretó la Reserva Biológica Cerro la Vueltas, con una superficie de 2500 hectáreas que protege parte de los páramos y los robledales de altura. La situación provocó un nuevo descontento entre de los habitantes de la reserva, quienes vieron limitados sus espacios productivos así como la prohibición para extraer recursos del bosque.

Siguiendo esa línea de acción, en 2005 se habló de la creación del Parque Nacional Los Quetzales en los alrededores de la Carretera Interamericana Sur, Providencia de Dota y el Cerro Buena Vista (Cerro de la Muerte) en parte de la Reserva Forestal Los Santos. Al igual que en otras ocasiones, los pobladores de la región se preocuparon y llevaron su pronunciamiento ante la Municipalidad por desconocer: "cuál sería su situación en cuanto a políticas y actividades para el desarrollo sostenible de las áreas de conservación". ${ }^{41}$ Los dirigentes comunales tomaron mayores preocupaciones y se valoraron los casos donde la creación de zonas protegidas abarcó límites mayores a los esperados. Además, se expuso cómo el parque cambiaría el estilo de vida de los habitantes por las nuevas políticas de protección y de los beneficios que traería a la zona y al país. ${ }^{42}$ El Parque Nacional Los Quetzales se creó en 2006 pero siguió la preocupación por la posible creación de más parques dentro de la Reserva Forestal Los Santos. A raíz de eso, en comunicados oficiales del MINAE a la Municipalidad de Dota se informó que: "por el momento no se crearán más parques nacionales en la Reserva Forestal Los Santos". "Pero aunque cesó la creación de parques en la zona, se dejó sin atender otro serio problema, la titulación de tierras. Esta lucha de los habitantes de las zonas protegidas en Dota continúa en la actualidad y se ha convertido en uno de sus mayores problemas. En síntesis, el sentimiento conservacionista con el que algunos lugareños intentaron combatir a otros actores sociales como la compañía maderera terminó jugando en su contra, pues no solo algunas comunidades quedaron dentro de áreas protegidas, sino que actualmente existen fuertes controles sobre el uso y titulación de sus tierras lo cual mantiene una fuerte tensión entre la comunidad y las autoridades.

En el otro caso, la zona que ahora ocupa el actual Refugio de Vida Silvestre Caño Negro estuvo habitada por indígenas maleku y desde inicios del siglo XX por nicaragüenses que ingresaron por vía fluvial en busca de hule y peces; pero la mayor cantidad de

\footnotetext{
${ }^{39}$ ANCR, Fondo Municipal, Sig. 16278, 1978, F. 264

${ }^{40}$ Municipalidad de Dota, Libro de Actas No 18, 1991, F. 24. "Solicitud reforma Reserva Forestal. La municipalidad acuerda dirigirse al Sr. Ministro de Recursos Naturales, Energía y Minas, solicitándole atentamente gestionar ante quien corresponda para que se reforme la ley o decreto que establece la reserva forestal del cantón de Dota, con el fin de que se amplíe el área habitacional, ya que en el distrito Copey para obtener escritura de terreno deberá ser una hectárea como mínimo y hay personas que no pueden comprar esa área o padres de familia que no podrán heredar a sus hijos terrenos con esas dimensiones. Creemos que una reforma permitirá a más gente poseer propiedad y distribuir en mejor forma."

${ }^{41}$ Municipalidad de Dota, Libro de Actas No 25, 2005, F. 328.

42 Ibid.

${ }^{43}$ Ibid, FF. 373-375
} 
población que se asentó en Caño Negro llegó en la segunda mitad del siglo XX con la apertura de caminos ${ }^{44}$ Los habitantes de Caño Negro dependieron en gran medida de la pesca, cuyo producto era salado y secado al sol para su venta en Nicaragua.

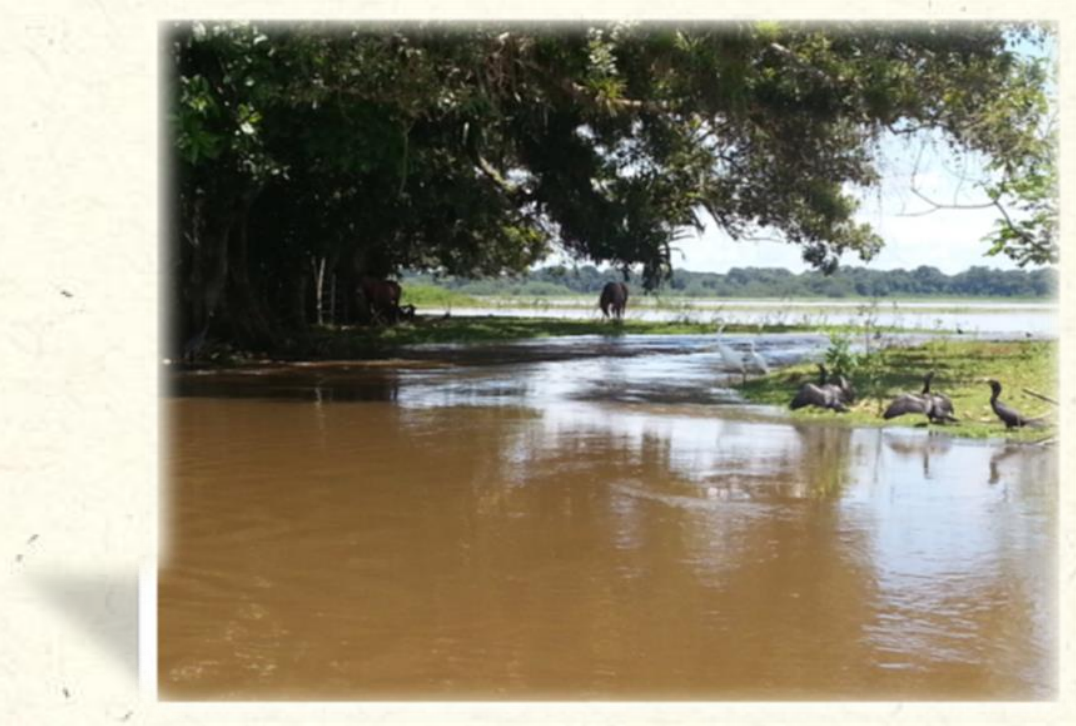

Image 1 - Proceso de llenado de las lagunas tras el desbordamiento del río Frío. En primer plano el río Frío y al fondo parte de la Laguna Caño Negro. Fotografía tomada en octubre de 2013.

Esa actividad fue auspiciada por la riqueza natural de la zona donde existe un sistema lagunar que provee distintos tipos de peces, entre ellos el más característico y representativo es el pez Gaspar (Atractosteus tropicus). Pero además de la extracción de peces y de hule (caucho natural), la población utilizaba las hojas de yolillo (Raphia taedigera) para los techos de las casas y de los graneros. Asimismo, la actividad ganadera, asociada al ciclo de llenado y vaciado del sistema lagunar, aportó a la dieta alimenticia de los lugareños y esto se complementó con las actividades propiamente agrícolas que se desarrollaban en la zona.

El humedal posee una gran diversidad biológica y además constituye un sitio de paso para aves migratorias lo cual en conjunto hizo que el Estado lo declarara Refugio Nacional de Vida Silvestre en 1984 con un área total de 9969 hectáreas. Sin embargo, se constituyó como un refugio mixto lo cual implica que hay propiedad privada y propiedad estatal, situación que acarrea uno de los principales problemas que enfrenta la población, pues algunos de ellos no poseen títulos sobre su tierra y ahora están imposibilitados para obtenerlo y deben conformarse con el usufructo de la tierra. Pero lo que nos interesa rescatar es que en el proceso de creación del refugio no se tomó en cuenta a los pobladores que por décadas habían vivido a la par de las lagunas y explotado sus recursos. ${ }^{45}$ En efecto un entrevistado señaló que "cuando se dieron cuenta ya eso era un

\footnotetext{
${ }^{44}$ Hasta bien entrada la segunda mitad del siglo XX la única vía de comunicación para llegar a Caño Negro era fluvial. Mediante el cauce del río Frío se podía llegar a Los Chiles o hasta San Carlos de Nicaragua.

${ }^{45}$ Solo uno de los entrevistados recordó que en esos años se pidió a algunas personas su opinión respecto a la creación del refugio. Este mismo entrevistado opinó que los̄ disconformes con el refugio son aquellos que ahora no pueden talar ni cazar animales.
} 
refugio". En un estudio realizado dos años después de creado el refugio, Camacho, Martín y Rodríguez ${ }^{46}$ recopilan criterios de los pobladores como los siguientes:

- Estoy de acuerdo en que prohíban la pesca pero no la tala de árboles.

- Favorable, mientras no afecte la forma de trabajo o se nos perjudique.

- Bueno pero que no se tengan daños (en la agricultura).

- Es bueno que cuiden y prohíban exageraciones, pero hay animales dañinos que se comen los alimentos de la gente.

- Desfavorable porque en la pobreza de uno lo perjudican prohibiéndolo todo.

- Los pobres somos los que más lo hemos sentido.

De estos argumentos se puede concluir que la comunidad realmente no conoció o recibió un proceso de información sobre el significado que tendría la creación del refugio. Como consecuencia de esto, no se logró acercar la comunidad al proyecto de conservación y por el contrario fortaleció la preocupación sobre el acceso a los recursos, incluso de sus propias fincas. Desde entonces ha sido común que se presenten incendios forestales, denuncias por tala y caza ilegal, así como denuncias por la apertura de canales artificiales que los finqueros hacen para drenar sus terrenos y usarlos en actividades agrícolas o pecuarias.

Lo cierto es que hoy el refugio muestra signos de deterioro y no existe claridad de quienes son los responsables o cómo resolverlo. La gente de Caño Negro advierte que la creación de asentamientos campesinos en las cercanías del refugio ha sido negativa pues mucha gente llega a pescar y cazar sin los permisos del MINAE. A esa situación suman la llegada de precaristas que se han instalado en las cercanías del sistema lagunar lo cual origina mayor presión sobre los recursos. Pero a pesar de estas situaciones y de la tensión ambiental evidente en la zona, pareciera improbable que se origine un conflicto propiamente ambiental ya que existen "válvulas de escape" que contienen las inquietudes de la gente. Por ejemplo, la escaza vigilancia por parte del MINAE, debido a falta de personal y de presupuesto, permite que los pobladores y los vecinos del lugar aprovechen los recursos sin ajustarse necesariamente a las políticas del área protegida. Por otro lado, aunque se dan denuncias y que el Tribunal Ambiental ejecuta las denominadas barridas ambientales, la aparente impunidad de muchos casos alienta a la gente a continuar con ciertas prácticas. En ese sentido, la caza y pesca ilegal permite suplir algo más que las necesidades alimenticias de la población y en particular esto se ha visto demostrado con algunos hallazgos de restos de cocodrilos que son asesinados para quitarles la piel y venderla en el mercado negro.

En síntesis, la compleja situación del Refugio de Vida Silvestre Caño Negro se puede atribuir a dos factores fundamentales. Por un lado, un proceso de constitución que no tomó en cuenta la experiencia de la gente y su dinámica sociocultural, lo cual no favorece la apropiación de un proyecto de esta naturaleza por parte de los involucrados. Por otro, resulta claro que no existió un acompañamiento real ni antes ni después de creado el refugio lo cual se manifiesta en el estado de semi-abandono en que se encuentra tanto el refugio como la comunidad, aspectos que por supuesto no son preocupantes para quienes dirigen el SINAC y el CONAC.

\footnotetext{
${ }^{46}$ Camacho Soto, Antonieta; Martín Salazar, Ligia y Rodríguez Cervantes Silvia (1986). "Características sociales, económicas y culturales del Refugio de Vida Silvestre Caño Negro". San José, Ministerio de Recursos Naturales Energía y Minas, Dirección General de Vida Silvestre, mimeögrafiado. BIO-DOC, signatura 1601.
} 


\section{Conservación y cambio económico}

El fuerte impulso a la conservación en Costa Rica coincidió con una coyuntura de cambio económico motivado en parte por las fuertes repercusiones de crisis externas como la del petróleo, iniciada en 1973 y que en nuestro país tuvo su extensión hasta entrada la década de 1980. Por ejemplo, a inicios de la década de 1970 la inflación era del margen de 3 a 5\%, para 1980 era del 17,8\% y en 1981 alcanzó la histórica tasa de $81,8 \%$. En esos primeros años de la década de 1980 los costarricenses experimentaron una devaluación de su moneda que pasó de 8,6 colones por dólar a más de 60 colones por dólar, ${ }^{47}$ lo que encareció los precios de los productos importados y provocó un desabasto incluso de alimentos básicos.

La premisa que acompaña nuestro análisis en este caso es que el gobierno entendió la importancia de impulsar el desarrollo turístico como un medio para atraer divisas ante la significativa merma de las exportaciones tradicionales provocada por la crisis en los precios del petróleo. Pero hay un indicador que pasa desapercibido usualmente y es que ya desde 1971 el Aeropuerto Internacional del Coco fue rebautizado como Aeropuerto Internacional Juan Santamaría y dada su importancia para el arribo de vuelos internacionales se dio inicio a una serie de mejoras para hacerlo más ágil. En ese contexto la política de conservación no había "despegado" pero sin duda alguna los dirigentes de la época advertían que la riqueza de nuestros espacios naturales constituía un rubro por explotar.

Gráfico 7 - Aporte de divisas del turismo y otras actividades económicas 1979-2014.

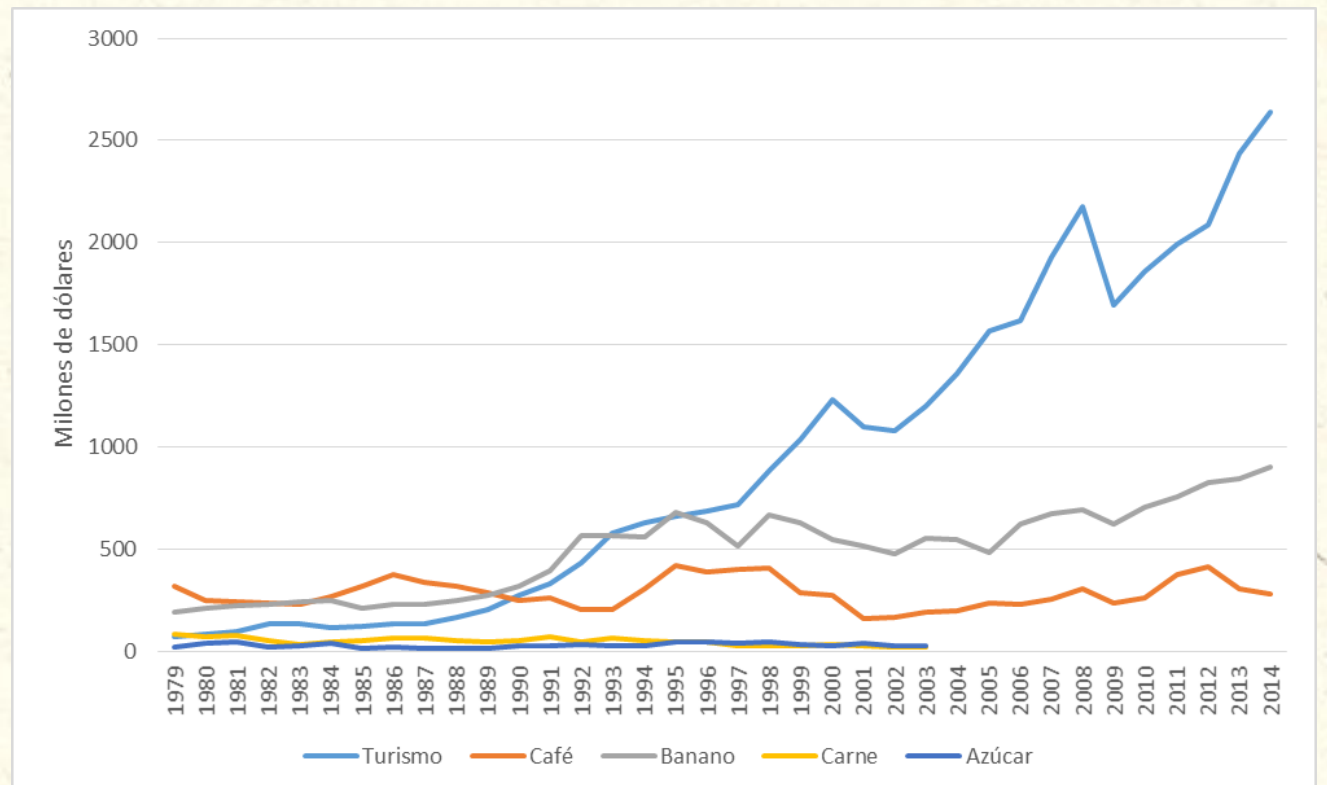

Fuente: Elaboración propia con base en datos de CANATUR y del ICT para el periodo 1979-2003 (citados por Shirley Benavides, Escuela de Economía de la UNA). Datos del Banco Central de Costa Rica (BCCR), Departamento de Estadística Macroeconómica para el periodo 2004-2014 (ICT, Anuario estadístico 2014).

\footnotetext{
${ }^{47}$ Carazo Chanto Steve (sin fecha). Implicaciones de la crisis de los años 1980 en el modelo económico de la actualidad. San José, Costa Rica, Ministerio de Hacienda, pag 13. Disponible en:

http://www.hacienda.go.cr/centro/datos/Articulo/Implicaciones\%20de\%20la\%20crisis\%20de\%20los\%20a\%C3\%B10s\%20oc henta.doc Consulta (12- febrero-2016)
} 
El gráfico anterior es contundente al mostrar el crecimiento sostenido de los ingresos derivados del turismo. En particular evidencia que desde inicios de la década de 1990 este rubro sobrepasó el ingreso de las actividades tradicionales de exportación, incluso ya para el 2002 las divisas por concepto de turismo eran superiores a la suma de lo obtenido por las exportaciones de café y banano. Este comportamiento obedece a una política de atracción muy fuerte relacionada con la "marca país" como un destino verde y esto se puede constatar con la afluencia sostenida de los turistas, incluso después de los atentados del 9/11 (11 setiembre de 2001) como se observa en el siguiente gráfico.

Gráfico 8 - Afluencia de turistas extranjeros a Costa Rica entre 1991 y 2014

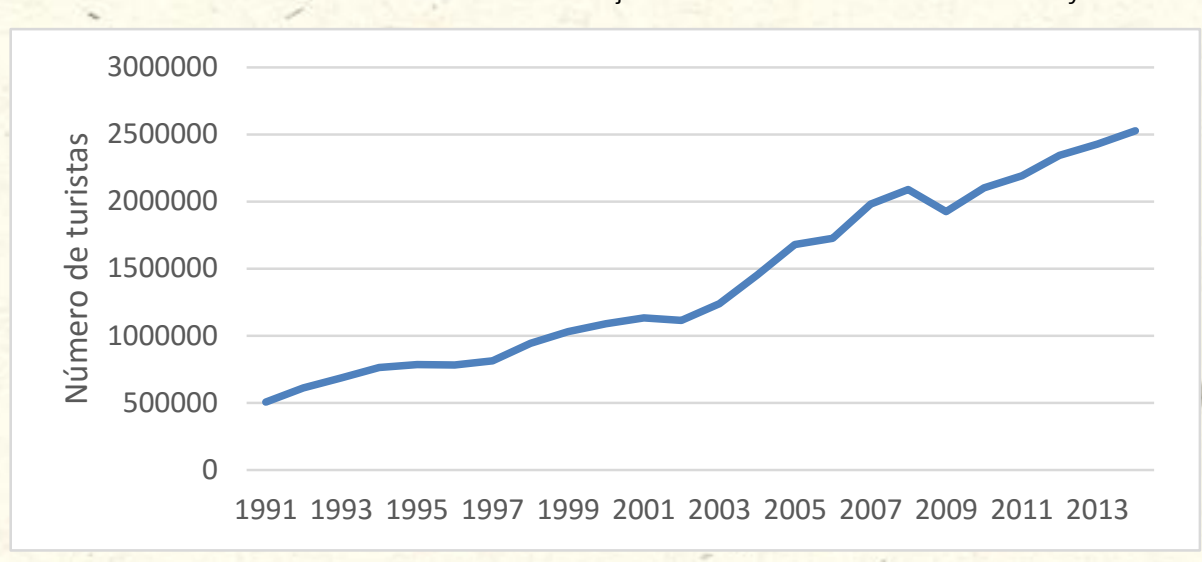

Fuente: Elaboración propia con base en datos del Estado de la Nación. Compendio estadístico de Economía.

Si vemos el comportamiento de estos visitantes en el país nos damos cuenta de que la visitación de áreas protegidas sufrió levemente a mediados de la década de 1990 pero luego muestra una tendencia de crecimiento leve que tampoco se alteró con los sucesos del 9/11. El haber superado estos "picos de tensión" sin mayor tropiezo le demostró a los costarricenses que la denominada "industria sin chimeneas" constituía una actividad próspera y menos sujeta a las condiciones internacionales. Esa situación provocó de inmediato que se impulsaran nuevos proyectos hoteleros y que nuevamente se entrara a ejecutar remodelaciones en el aeropuerto Juan Santamaría así como en el Aeropuerto Daniel Oduber Quirós en Liberia, Guanacaste, ciudad próxima al principal polo turístico del país.

Gráfico 9 - Visitantes nacionales y extranjeros en las áreas protegidas de Costa Rica, en porcentajes, 19902014.

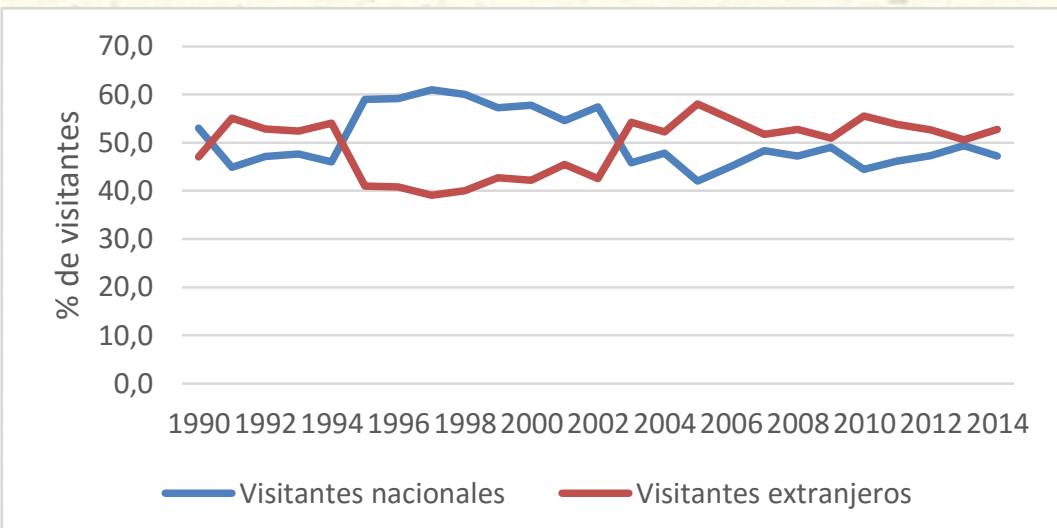

Fuente: Elaboración propia con base en datös del Estado de la Nación. Compendio estadístico Ambiental. 
Asimismo, las condiciones creadas para el turismo internacional poco a poco se fueron volviendo "en contra" del turismo nacional pues los servicios se empiezan a tasar en dólares. Así, del gráfico anterior podemos extraer dos lecturas; la más clara es la complementariedad entre ambos tipos de visitantes de las áreas protegidas, pero al mismo tiempo se puede ver que por más de una década el turismo nacional no llega al 50\% del total de visitantes lo cual hace suponer que posiblemente estén asistiendo a un tipo de turismo tradicional.

Pero no obstante esas variaciones, es importante destacar que el turismo como actividad generadora de divisas ha mantenido una tendencia al alza. Y aunque su aporte total al PIB ha fluctuado mucho, su representatividad como parte del total de exportaciones lleva una tendencia creciente como se muestra en las dos gráficas que se presentan a continuació

Gráfico 10 - Aporte del Turismo al PIB, en porcentajes.

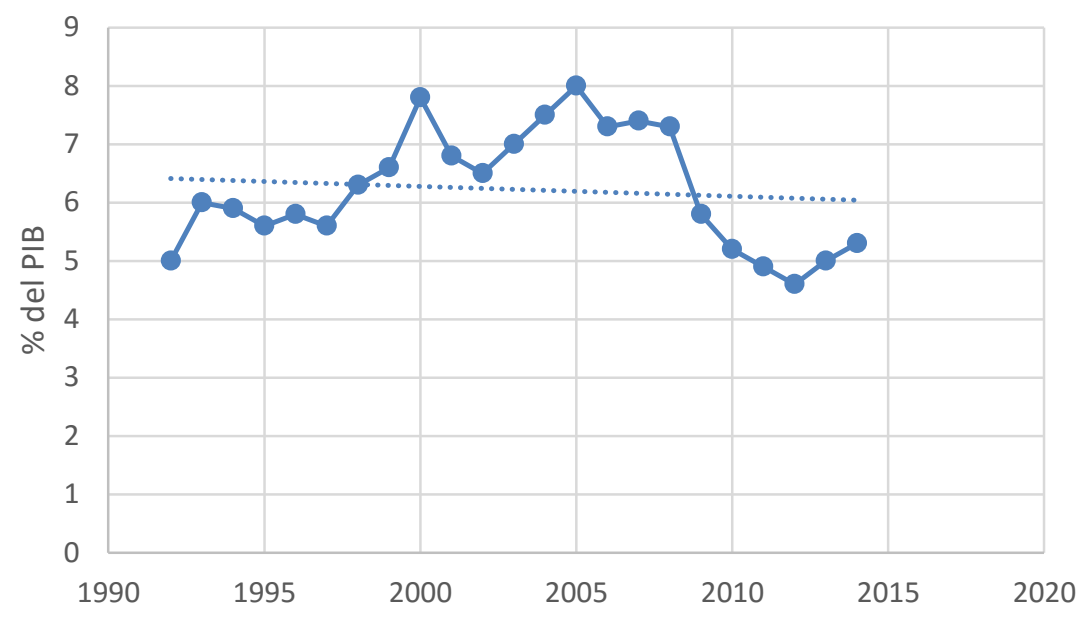

Fuente: Elaboración propia con base en datos del Estado de la Nación. Compendio estadístico de Economía.

Gráfico 11 - Aporte del Turismo como parte de las exportaciones, en porcentajes

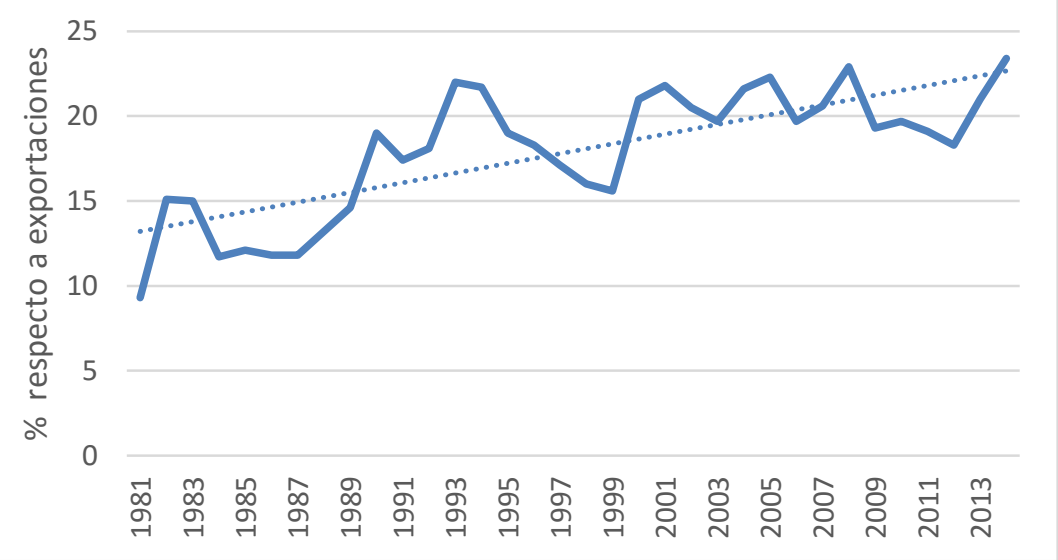

Fuente: Elaboración propia con base en datos de CANATUR y del ICT para el periodo 1979-2003 (citados por Shirley Benavides, Escuela de Economía de la UNA). Datos del Banco Central de Costa Rica (BCCR), Departamento de Estadística Macroeconómica para el periodo 2004-2014 (ICT, Anuario estadístico 2014). 
Ahora bien, lo que es aún más significativo de este fenómeno es reconocer cuál es el aporte de las áreas protegidas al ingreso total por concepto de turismo. Para acercarnos a ese dato vamos a citar un estudio realizado por el Centro Internacional de Política Económica (CINPE) de la Universidad Nacional de Costa Rica en cooperación con el Instituto Nacional de Biodiversidad (INBio). Según este trabajo, basado en datos del instituto Costarricense de Turismo (ICT):

para los tres primeros trimestres de 2002, entre un $45 \%$ y un $50 \%$ de los turistas que visitaron Costa Rica en ese año, realizaron actividades relacionadas con la visita a volcanes, observación de flora y fauna y caminatas por senderos. Suponiendo -con base en los motivos y destinos reportados por el ICT- que el $50 \%$ del total de turistas extranjeros ha sido atraído principalmente por esas áreas silvestres protegidas, éste ha generado el $50 \%$ del total de los ingresos obtenidos a nivel nacional por concepto de turismo en general. ${ }^{48}$

De la anterior se desprenden dos lecturas. La primera positiva, motivada por el aporte sustantivo que las áreas protegidas ofrecen a la economía nacional, esto sin considerar los miles de empleos, directos e indirectos que generan en toda la cadena. Esta primera lectura nos lleva a concluir que las políticas de proyección de la "marca país" han sido exitosas y que hoy Costa Rica es visto a escala internacional como un espacio idóneo para el turismo natural o ecoturismo. Pero también es posible hacer una lectura negativa, pues pese a la importancia de esta actividad, los millones de dólares en divisas que ingresan por este concepto y su aporte global al PIB nacional, la inversión nacional en ambiente es muy limitada, especialmente en infraestructura que permita a las áreas protegidas ofrecer a los turistas una mejor experiencia de visitación. Este fenómeno sin duda explica la situación de abandono en que encuentran algunas áreas protegidas del país, como el caso del Refugio de Vida Silvestre Caño Negro.

Pero además de eso, también es importante señalar la necesidad de que se invierta en acciones que mejoren la distribución de los ingresos entre los diferentes actores de la cadena. Según datos presentados por Lawrence Pratt ${ }^{49}$ para 1998, podría decirse que solo el 21 por ciento de los gastos diarios de un turista están en posibilidad de llegar a manos de pequeños "empresarios locales" por concepto de hospedaje y alimentación. Sin embargo, ese porcentaje podría ser en muchos casos solo del 8,7 por ciento (lo que corresponde a alimentación) dado que no todo el turista que llega a las áreas protegidas se queda en ellas.

En relación con eso podemos mencionar el trabajo de Gilbert Vargas quien realizó una pequeña tipología de lo que él denomina turistas de la naturaleza o ecoturistas en la que cita a los turistas de naturaleza: casual, ocasional, vocacional, bien informado y científico. ${ }^{50} \mathrm{De}$ estos cinco tipos, los últimos dos son los que con mayor regularidad se trasladan a un área protegida y permanecen en ella por un periodo determinado haciendo uso de los servicios que ofrece la comunidad, los otros tres generalmente corresponden a turistas de un día. ${ }^{51}$ Lo

\footnotetext{
${ }^{48}$ Fürst, Edgar, Mary Luz Moreno, Daniela García y Edwin Zamora (2002). "Sistematización y análisis del aporte de los parques nacionales y reservas biológicas al desarrollo económico y social en Costa Rica: los casos de los parques nacionales Chirripó, Cahuita y Volcán Poás". Resumen ejecutivo. Costa Rica, CINPE, pp 3-4.

${ }^{49}$ Pratt, Lawrence (2002). "Logros y retos del turismo costarricense". Costa Rica, CLACDS, p8. En este trabajo Pratt se basa en "Encadenamientos globales de producción: consumidores del norte, productores del sur y sostenibilidad" trabajo realizado por el INCAE en 1998

50 Vargas Ulate, Gilbert. p 51.

${ }^{51}$ La mayoría de agencias de viajes y tour operadores de Costa Rica ofrecen al turista la opción de viajes de un día. De esta forma, si un extranjero compra tres tours de este tipo debe triplicar su costo en el rubro de transporte lo cual beneficia indudablemente a un sector de la cadena.
} 
que resta decir es que los turistas de naturaleza "bien informados y científicos" corresponden a un grupo muy reducido usualmente relacionado con sectores académicos por lo que su representatividad es baja.

\section{A manera de conclusión}

Sin llegar a ser exhaustivo, el análisis presentado hasta aquí nos permitió enfocarnos en varios aspectos que, desde nuestro criterio, ayudan a demostrar que la visión que se tiene sobre una Costa Rica preocupado por el ambiente es lo que nosotros definiríamos como una verdad a medias. Sin lugar a dudas, y así queda demostrado, hay una preocupación real por el ambiente y eso ha conducido a tal nivel de burocratización en la gestión ambiental. Pero es igualmente cierto que ese modelo de conservación que se ha implementado desde la década de 1970 requiere de una reforma pues se muestra agotado e ineficaz para las demandas actuales. El contexto y las necesidades del mismo sistema claman por una mayor participación ciudadana en la gestión y manejo de las áreas silvestres protegidas, pero una participación real que incluya también el goce de los beneficios económicos que derivan de él. Apostar por ese cambio significa obviamente "tocar" intereses creados en torno a la actividad del turismo, pues como es conocido por todos, tenemos políticos que abandonaron sus "intereses agrícolas" y hoy son inversionistas en complejos hoteleros. Pero apostar por ese cambio también implica una reingeniería de la estructura administrativa de instancias como el MINAE, SINAC, CONAC y CONAGEBIO, entre otras. Se requiere de políticas que ocasionen un cambio de paradigma mediante el cual se asuma que la conservación va más allá de "poner especies detrás de una vitrina". Se necesita bio-alfabetizar a la población pero también aprovechar las experiencias bioculturales de los pueblos en un esfuerzo conjunto por contener el daño ambiental. Pero para ello también es necesario que el Estado eleve el presupuesto dedicado al ambiente pues no se puede esperar mejoras sustantivas con insumos insignificantes. Está demostrado que el turismo y en particular el turismo en áreas silvestres protegidas aporta un porcentaje significativo al PIB nacional y lo menos que se puede hacer es exigir a las autoridades mejores condiciones para quienes viven y trabajan por el resguardo y conservación de nuestros recursos.

En este pequeño acercamiento a la realidad de la conservación en Costa Rica hemos graficado algunos datos que nos permiten concluir al menos dos cosas concretas. Por un lado es evidente que la política de conservación guarda una estrecha relación con la coyuntura de cambio económico y que las iniciativas para consolidar una "marca país" jugaron un papel trascendental en la orientación que ha tomado esta actividad en particular desde 1990. El éxito del desarrollo turístico también está asociado a su flexibilidad y capacidad para adaptarse a un público con distintos intereses pero especialmente por su menor vulnerabilidad ante los altibajos de la economía mundial. La otra conclusión es aún más contundente: hoy el turismo es la principal entrada de divisas con que cuenta el país y por ende es lógico pensar que requiere de mayor atención por parte del Estado de manera que se potencie su desarrollo desde distintos flancos y que sus beneficios lleguen a la mayor cantidad de personas bajo esquemas de una economía solidaria.

Entendemos claramente que modificar un modelo de conservación como el actual implica un esfuerzo de proporciones insospechadas, pero también sabemos que se ha avanzado sustantivamente en esquemas de gobernanza bajo el esquema de comanejo. A esto se le pueden sumar iniciativas exitosas que se han conocido desde el impulso a las pequeñas y medianas empresas PYMES, especialmente aquellas ligadas al ecoturismo. También es oportuno rescatar las experiencias de cooperativización de servicios y de 
actividades agroindustriales que han demostrado que el modelo cooperativo podría ser eficaz si se implementa de manera sistemática en la cogestión de los recursos, entre otras iniciativas.

Para cerrar, es importante indicar que Costa Rica si es un país exitoso en el campo de la conservación, pero que detrás de eso hay una serie de problemas que usualmente son invisibilizados. Como ejemplo solo hemos mencionado dos casos (Dota y Caño Negro) pero así como ellos hay otras comunidades cercanas a las áreas protegidas que sufren de situaciones similares y las autoridades no actúan de manera oportuna. Por ejemplo, a pesar de los ingresos que se obtienen del turismo, el Estado no ha sido capaz de comprar las tierras a los propietarios que quedaron dentro de alguna área protegida pero tampoco ha mejorado las condiciones de esas áreas para que las comunidades puedan beneficiarse de los servicios ecosistémicos que se ofrecen en ellas y de esa manera mejorar su situación socioeconómica. 